\title{
Presynaptic Glycine Receptors on GABAergic Terminals Facilitate Discharge of Dopaminergic Neurons in Ventral Tegmental Area
}

\author{
Jiang-Hong Ye, ${ }^{1}$ Fushun Wang, ${ }^{1}$ Kresimir Krnjević, ${ }^{2}$ Weizhen Wang, ${ }^{3}$ Zhi-Gang Xiong, ${ }^{3}$ and Jingli Zhang ${ }^{1}$ \\ ${ }^{1}$ Departments of Anesthesiology, Pharmacology, and Physiology, New Jersey Medical School, Newark, New Jersey 07103, ${ }^{2}$ Physiology Department, McGill \\ University, Montréal, Quebec H3G 1Y6 Canada, and ${ }^{3}$ Robert S. Dow Neurobiology Laboratories, Legacy Research, Portland, Oregon 97232
}

\begin{abstract}
GABA-mediated postsynaptic currents (IPSCs) were recorded from dopaminergic (DA) neurons of the ventral tegmental area (VTA) of rats, in acute brain slices, and from enzymatically or mechanically dissociated neurons. In young rats (3-10 d of age), where GABA is

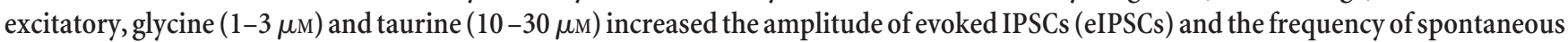
IPSCs (sIPSCs) but had minimal postsynaptic effects. Strychnine $(1 \mu \mathrm{M})$ blocked the action of glycine; when applied alone, it reduced the amplitude of eIPSCs and the frequency of sIPSCs, indicating a tonic facilitation of GABAergic excitation by some endogenous glycine agonist(s). In medium containing no $\mathrm{Ca}^{2+}$, or with $\mathrm{Cd}^{2+}$ or tetrodotoxin added, the amplitude and especially the frequency of sIPSCs greatly diminished. In many cells, glycine had no effect on remaining miniature IPSCs, suggesting a preterminal site of glycine receptors (GlyRs). Fura-2 fluorescent imaging showed a glycine-induced increase of $\left[\mathrm{Ca}^{2+}\right]$ in nerve terminals (on DA neurons), which was suppressed by strychnine or $3 \mu \mathrm{M} \omega$-conotoxin MVIIA. Therefore, the presynaptic GlyR-mediated facilitation of GABAergic transmission seems to be mediated by $\mathrm{N}$ - and/or P/Q-type $\mathrm{Ca}^{2+}$ channels. In older rats (22-30 $\mathrm{d}$ of age), where GABA causes inhibition, the effect of strychnine on GABAergic IPSCs was reversed to facilitation, indicating a tonic glycinergic inhibition of GABA release. Furthermore, glycine $(1-3 \mu \mathrm{M})$ reduced the amplitude of eIPSCs and the frequency of sIPSCs. Hence, the overall effect of the presynaptic action of glycine is to enhance the firing of DA cells, both in very young and older rats.
\end{abstract}

Key words: IPSCs; synaptic transmission; calcium channels; whole-cell patch clamp; strychnine; taurine; mesolimbic system

\section{Introduction}

Ionotropic neurotransmitter receptors on presynaptic nerve endings in the PNS and CNS (McGehee and Role, 1996; MacDermott et al., 1999) often inhibit synaptic transmission (Eccles et al., 1963; Lerma, 1997; Casado et al., 2000; Frerking and Nicoll, 2000; Satake et al., 2000). In adults, glycine is an inhibitory neurotransmitter because it induces $\mathrm{Cl}^{-}$influx (Werman et al., 1968; Krnjević, 1974; Nicoll et al., 1990; Kuhse et al., 1995). However, during early development, like GABA (Mueller et al., 1984; Cherubini et al., 1991), glycine can be excitatory because the intracellular concentration of $\mathrm{Cl}^{-}$is relatively high (Ben-Ari et al., 1997; Ehrlich et al., 1999; Rivera et al., 1999; Zhou, 2001; Kilb et al., 2002; Laube et al., 2002). Glycine receptors (GlyRs) on nerve terminals can either inhibit or increase transmitter release. They reduce vasopressin release in the neurohypophysis (Hussy et al., 2001), but they enhance EPSCs in a pontine auditory nucleus (Turecek and Trussell, 2001) and the cerebellar cortex (Kawa, 2003) as well as glycinergic IPSCs of spinal (Jeong et al.,

Received March 9, 2004; revised Aug. 16, 2004; accepted Aug. 16, 2004.

This study was supported by National Institutes of Health Grants AA-11989 (J.-H.Y.), AT001182 (J.-H.Y.), and NS42926 (Z.-G.X.).

Correspondence should be addressed to Jiang-Hong Ye, Department of Anesthesiology, New Jersey Medical School, 185 South Orange Avenue, Newark, NJ 07103-2714. E-mail: ye@umdnj.edu.

DOI:10.1523/JNEUROSCI.2016-04.2004

Copyright $\odot 2004$ Society for Neuroscience $\quad$ 0270-6474/04/248961-14\$15.00/0
2003) and cerebellar (Kawa, 2003) neurons. No comparable presynaptic modulation of GABAergic transmission by glycine has been observed in the ventral tegmental area (VTA). Unlike the above areas, the VTA has a relatively sparse glycinergic innervation (Rampon et al., 1996).

The mesolimbic dopaminergic (DA) system, originating in the VTA, mediates the rewarding effects of drugs of abuse, including ethanol (Gatto et al., 1994; Wise, 1996; Rodd et al., 2004). The discharge of VTA DA neurons is modulated by GABAergic synapses (Johnson and North, 1992; Xi and Stein, 1998; Tepper et al., 1998), which seem to regulate ethanol consumption (Nowak et al., 1998; Melis et al., 2002). However, little is known about other factors that may govern this GABAergic inhibition of DA neurons.

Although glycine is best known as a transmitter in the spinal cord and brain stem, GlyRs are found throughout the CNS (Betz, 1991), including the VTA (Rampon et al., 1996; Ye et al., 1998; Ye, 2000; Zheng and Johnson, 2001). We therefore probed more deeply the function of GlyRs in the VTA, notably their possible role in the modulation of GABAergic input to the DA neurons. With this purpose in mind, we recorded GABA-mediated IPSCs in mechanically isolated DA neurons ("nerve-bouton preparations"). Because functional nerve terminals remain attached to such neurons (Akaike and Moorhouse, 2003), any presynaptic glycinergic actions should be revealed by applications of glycine 
and strychnine (STR) (the classical antagonist of GlyRs). For confirmation under more physiological conditions, similar tests were repeated on VTA DA neurons in midbrain slices. Keeping in mind that $\mathrm{Cl}^{-}$-mediated transmitter actions in rats reverse from depolarization to hyperpolarization during postnatal ontogeny (Rivera et al., 1999), we compared glycinergic effects recorded within 3-4 d after birth and 3-4 weeks later. A major finding of these experiments is that ongoing release of an endogenous agonist (perhaps taurine, which is present in the brain in large amounts, especially during the early postnatal period) (Sturman, 1993 ) exerts a tonic modulation of GABAergic transmission. The net result is to enhance DA neuronal firing in both young and more mature rats. Parts of these data are briefly summarized in a recent abstract (Ye et al., 2004).

\section{Materials and Methods}

Slice preparation and mechanical dissociation. Most of the experiments were done on brains from very young Sprague Dawley rats (at postnatal days 3-10) as well as, for comparison, some brains from older rats (22-30 $\mathrm{d}$ of age). The midbrain slices were prepared as described previously (Ye et al., 1998; Bonci and Malenka, 1999). In brief, rats were decapitated. The midbrain was isolated and sliced in the horizontal plane (250-300 $\mu \mathrm{m}$ ) with a Vibroslice (Campden Instruments, Leicester, UK) or a VF100 Slicer (Precisionary Instruments, Greenville, NC) while kept in icecold artificial CSF (ACSF) saturated with $95 \% \mathrm{O}_{2} / 5 \% \mathrm{CO}_{2}$ (carbogen) containing the following (in mM): $126 \mathrm{NaCl}, 1.6 \mathrm{KCl}, 1.2 \mathrm{NaH}_{2} \mathrm{PO}_{4}, 1.2$ $\mathrm{MgCl}_{2}, 2.4 \mathrm{CaCl}_{2}, 18 \mathrm{NaHCO}_{3}$, and 11 glucose. Slices (two per animal) were allowed to recover for at least $1 \mathrm{hr}$ in a holding chamber before they were placed in the recording chamber and superfused $(1.5 \mathrm{ml} / \mathrm{min})$ with carbogen-saturated ACSF.

Neurons with functional terminals attached were obtained by the method described by Akaike and Moorhouse (2003), with some modifications. Midbrain slices ( $300 \mu \mathrm{m}$ thick) were kept in carbogenated ACSF at room temperature $\left(21-24^{\circ} \mathrm{C}\right)$ for at least $1 \mathrm{hr}$ before mechanical dissociation. The slices were then transferred to a $35 \mathrm{~mm}$ culture dish (Primaria 3801; Becton Dickinson, Rutherford, NJ). For $\mathrm{Ca}^{2+}$-imaging experiments, $25 \times 25 \mathrm{~mm}$ glass coverslips were placed in a $35 \mathrm{~mm}$ culture dish. These dishes were filled with standard external solution containing the following (in mM): $130 \mathrm{NaCl}, 5 \mathrm{KCl}, 2 \mathrm{CaCl}_{2}, 1 \mathrm{MgCl}_{2}, 10 \mathrm{HEPES}, 11$ glucose $(320 \mathrm{mOsm}$, pH set to 7.4 with $\mathrm{NaOH})$. Under an inverted microscope (Nikon, Tokyo, Japan), VTA was identified medial to the accessory optic tract and lateral to the fasciculus retroflexus. A fire-polished glass pipette, lightly touching the surface of the VTA, was vibrated horizontally at $40-60 \mathrm{sec}^{-1}$ for $2 \mathrm{~min}$ by a homemade device. The slice was then removed. The isolated neurons adhered to the bottom of the dish or to the coverslip within $20 \mathrm{~min}$ and were then ready for electrophysiological and $\mathrm{Ca}^{2+}$-imaging experiments.

Electrophysiological recording. Whole-cell and loose-cell-attached patch-clamp configurations were used to record electrical activity with MultiClamp 700A or Axopatch 200B amplifiers (Axon Instruments, Foster City, CA), a Digidata 1320A analog-to-digital converter (Axon Instruments), and pClamp 9 software (Axon Instruments). Data were filtered at $2 \mathrm{kHz}$ and sampled at $10 \mathrm{kHz}$. The junction potential between the patch pipette and the bath solutions was nulled just before forming the giga-seal. The liquid junction potential between the bath and the electrode was $3.3 \mathrm{mV}$, as calculated from the generalized Henderson equation with the Axoscope junction potential calculator (Barry, 1996). This value was corrected off-line when estimating the reversal potential of glycine-activated currents. Taking into account an initial series resistance of $15-25 \mathrm{M} \Omega$, after the standard $80 \%$ compensation, there remained a 3-5 mV error for $1 \mathrm{nA}$ of current.

The patch electrodes had a resistance of 3-5 M $\Omega$ when filled with the following (in mM): $121 \mathrm{KCl}, 4 \mathrm{MgCl}_{2}, 11 \mathrm{EGTA}, 1 \mathrm{CaCl}_{2}, 10 \mathrm{HEPES}, 2$ Mg-ATP, and $0.1 \mathrm{GTP}$, the $\mathrm{pH}$ was adjusted to 7.2 with $1 \mathrm{~N} \mathrm{KOH}$, and the osmolarity to $280 \mathrm{mOsm}$ with sucrose. Throughout the experiments, the bath was continually perfused with the standard external solution (for the isolated neurons) or ACSF (for brain slices). All recordings were made in these solutions at an ambient temperature of $20-23^{\circ} \mathrm{C}$ unless otherwise indicated.

In brain slices, cells were visualized with an upright microscope (E600FN; Nikon) and infrared illumination. To evoke monosynaptic IPSCs, a bipolar (twisted nichrome wire) stimulating electrode was placed 50-100 $\mu \mathrm{m}$ rostral to the recording site in the VTA. Paired stimuli (100 $\mu \mathrm{sec}$ depolarizing pulses, $60 \mathrm{msec}$ apart) were given at the rate of $0.05 \mathrm{sec}^{-1}$. Loose-patch cell-attached (15-200 M $\Omega$ ) recordings from the soma of DA neurons were made with an ACSF-containing electrode. This technique yields stable recordings and minimizes the dialysis of intracellular components via the patch pipette (Kondo and Marty, 1998; Brodie et al., 1999; Carta et al., 2004).

Chemicals and applications. Most of the chemicals, including glycine, strychnine, bicuculline (BIC), and tetrodotoxin (TTX), were obtained from Sigma (St. Louis, MO). Fura-2 acetoxymethylester and $\mathrm{N}$-(3triethylammoniumpropyl)-4-(4-(dibutylamino)styryl) pyridinium dibromide (FM1-43) were from Molecular Probes (Eugene, OR). The solutions, prepared on the day of experimentation, were applied to a dissociated neuron via a multibarreled superfusion system consisting of five needles aligned and held together with heat-shrinkable plastic tubing and exiting into a common outflow tube (Ye et al., 1998). The barrels of the pipette were connected to separate reservoirs containing various drugs. Solutions were exchanged by simultaneously closing and opening valves controlling the flow from the reservoirs. These maneuvers were performed manually, and the flow was driven hydrostatically. The tip of the superfusion pipette was usually placed $50-100 \mu \mathrm{m}$ away from a cell, a position that allowed rapid as well as uniform drug applications while preserving the mechanical stability of the neuron. By keeping the dead volume small and the flow rate high, solutions could be exchanged within $30 \mathrm{msec}$. In experiments on brain slices, chemicals were added in known concentrations to the superfusate. The fact that $10 \mu \mathrm{m}$ bicuculline blocked most IPSCs (in slices) within $90 \mathrm{sec}$ is an indication of the effective bath exchange time.

$\mathrm{Ca}^{2+}$ imaging. Fura-2 fluorescent imaging was performed as described previously (Xiong et al., 2000). After $\sim 30$ min of recovery after mechanical dissociation, neurons were incubated for $30 \mathrm{~min}$ in $5 \mu \mathrm{M}$ fura-2acetoxymethyl ester at room temperature. They were then washed three times and incubated in dye-free solution for another $30 \mathrm{~min}$. Coverslips with fura-2-loaded cells were then transferred to a perfusion chamber on the stage of an inverted microscope (Nikon TE300) equipped with an epifluorescence attachment. The cells were illuminated by a xenon lamp $(75 \mathrm{~W})$ and observed with a $40 \times$ UV fluor oil-immersion objective lens (Nikon). Video images were obtained every $2-5 \mathrm{sec}$ by a cooled CCD camera (Sensys KAF 1401; PhotoMetrics, Tucson, AZ). Digitized images were acquired, stored, and analyzed in a personal computer controlled by imaging software Axon Imaging Workbench (AIW2.1; Axon Instruments). The shutter and filter wheel (Lambda 10-2; Sutter Instruments, Novato, CA) were also controlled by AIW to allow timed illumination of cells at either 340 or $380 \mathrm{~nm}$ excitation wavelengths. Fura-2 fluorescence was detected at an emission wavelength of $510 \mathrm{~nm}$. Backgroundsubtracted $340 / 380$ ratio images were analyzed by averaging pixel ratio values in circumscribed regions of interest. The values were exported from AIW to SigmaPlot 2000 (SPSS, Chicago, IL) for additional analysis and plotting. All imaging experiments were done at room temperature $\left(22^{\circ} \mathrm{C}\right)$.

FM1-43 staining. FM1-43 $(10 \mu \mathrm{M})$, a fluorescent dye commonly used for staining secretory vesicles or presynaptic terminals (Cochilla et al., 1999; Akaike and Moorhouse, 2003), was applied to neurons for $30 \mathrm{sec}$ in the presence of $45 \mathrm{~mm} \mathrm{~K}^{+}$and then washed out for $\sim 5 \mathrm{~min}$. FM1-43 fluorescence was viewed with an excitation/emission wavelength at 530/ $620 \mathrm{~nm}$. This water-soluble dye, which is virtually nonfluorescent in aqueous medium, is believed to penetrate the outer leaflet of the cell membrane, where it becomes intensely fluorescent. In a neuron that is actively releasing neurotransmitters, the dye is internalized within the recycled synaptic vesicles and so the nerve terminals become brightly stained. Nonspecific staining of cell-surface membranes can simply be washed off before viewing.

Data analysis. Spontaneous IPSCs (sIPSCs) were counted and analyzed using the MiniAnalysis program (Synaptosoft, Leonia, NJ). Spon- 
A

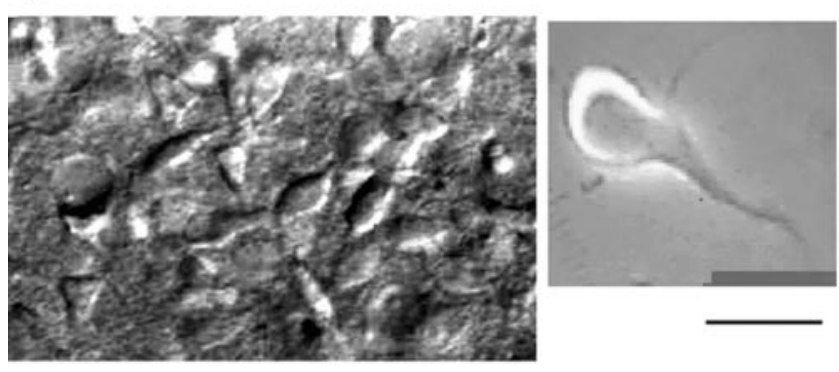

B
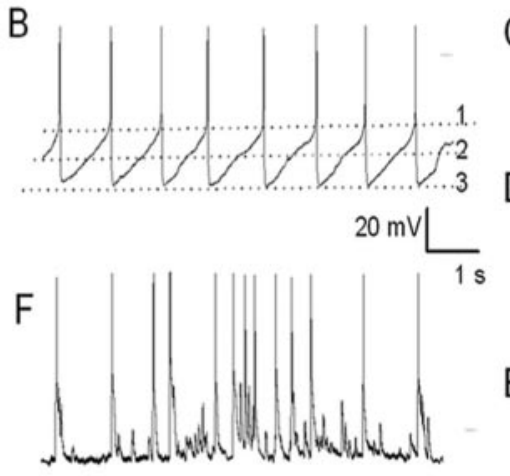

C

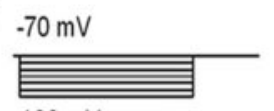

$-130 \mathrm{mV}$

D

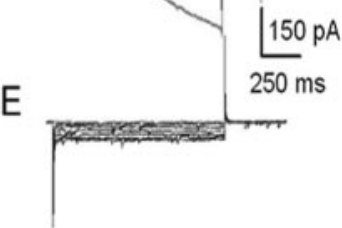

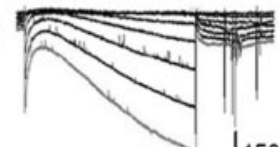

Figure 1. DA neurons in VTA have distinct electrophysiological properties. A, Left, Photomicrograph of neurons within a VTA slice (350 $\mu \mathrm{m}$ thick) obtained by near-infrared differential interference contrast illumination ( $40 \times$ water immersion objective) with a Nikon E600FN. Right, A mechanically dissociated fusiform VTA neuron. The much-reduced dendritic arbors of such cells facilitate space clamp. These nerve-bouton preparations often preserve functional synaptic boutons. Scale bar: slice, $100 \mu \mathrm{m}$; isolated neuron, $35 \mu \mathrm{m}$. B, Spontaneous firing recorded from a dissociated putative DA neuron. Dotted lines indicate the following: (1) the characteristically high spike threshold (approximately $-40 \mathrm{mV}$ ), (2) the resting membrane potential $(-55 \mathrm{mV})$, and (3) the prominent afterhyperpolarization, which decays into the onset of the next slow depolarization. $D$, Under voltage clamp, the currents induced in such a cell by a series of hyperpolarizing voltage pulses (the $10 \mathrm{mV}$ steps to $-130 \mathrm{mV}$ are illustrated in C) show the characteristic large inward relaxations $\left(I_{\mathrm{h}}\right)$. F, Irregular spontaneous firing of a dissociated putative GABAergic neuron; most of the spikes fired on the top of EPSPS. $E$, The current responses of such an interneuron show no inward relaxations $\left(I_{\mathrm{h}}\right)$.

taneous events were screened automatically using an amplitude threshold of $5 \mathrm{pA}$, checked visually, and accepted or rejected according to their rise and decay times. The frequency and amplitude of all events, during and after drug applications, were normalized to the mean values obtained during the control period. The interevent intervals and amplitudes of a large number $(100-50,000)$ of sIPSCs obtained from the same neuron were examined by constructing cumulative probability distributions, and these distributions were compared under different conditions using the Kolmogorov-Smirnov (K-S) test. For other plots, the frequency and amplitude of all events over a 1-2 min interval during the peak of a drug response were normalized to the average values of sIPSC [or miniature IPSC (mIPSC)] frequency and amplitude during the initial control period (5-15 min). The responses to pairs of stimulations were determined by averaging between 10 and 20 trials for each experimental condition. The amplitude of evoked IPSCs (eIPSCs) was measured with the Clampfit 9 program. Means ( \pm SEM) were normalized to the control values. Mean absolute amplitudes of eIPSCs were compared by Student's paired two-tailed $t$ tests. Values of $p<0.05$ were considered significant.

\section{Results}

All evoked responses were recorded from neurons in brain slices cut horizontally at the level of the VTA (Fig. $1 A$ ). Under infrared

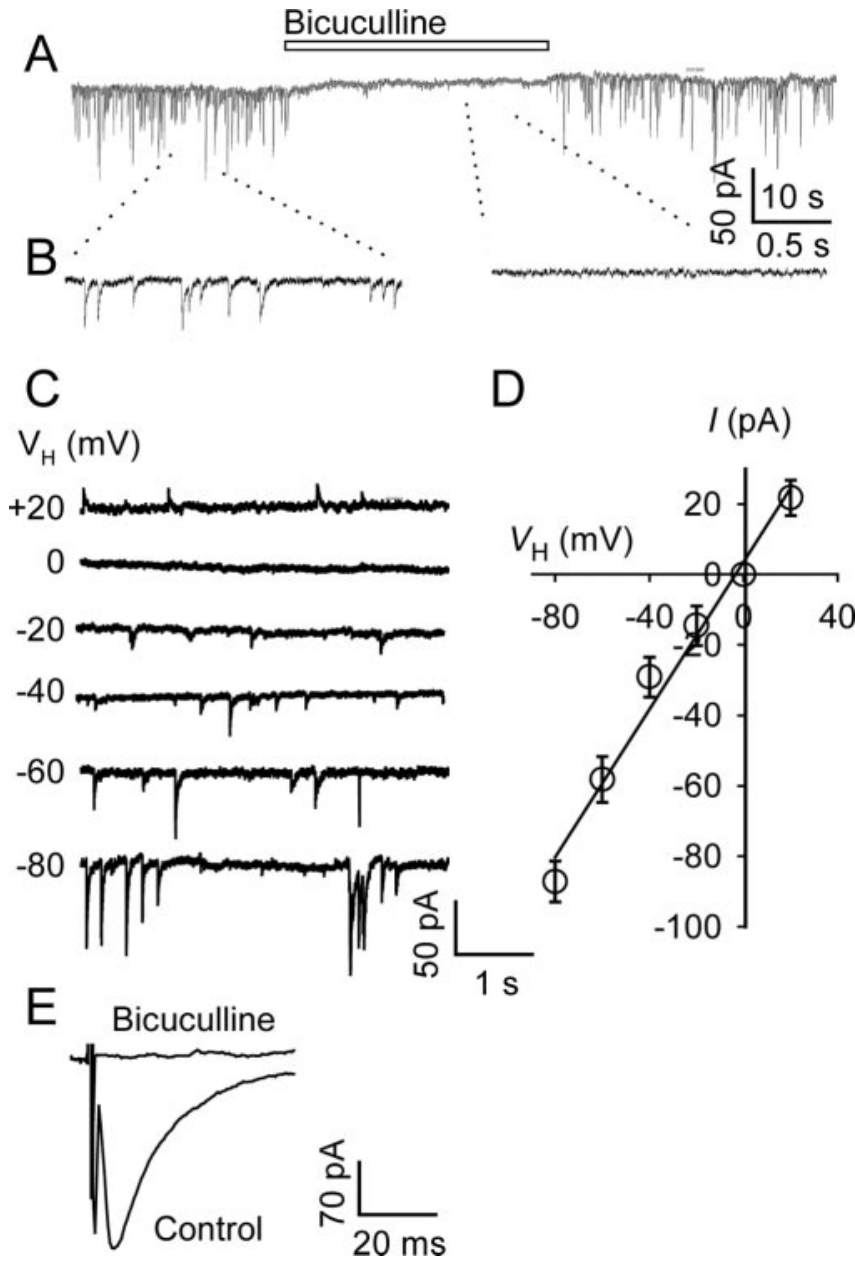

Figure 2. Spontaneous $G_{A B A_{A}}$ receptor-mediated IPSCs recorded in DA neuron mechanically isolated from VTA. $A$, In the presence of $50 \mu \mathrm{m}$ APV and $10 \mu \mathrm{m}$ DNQX, typical sIPSCs recorded at a holding potential $\left(V_{H}\right)$ of $-50 \mathrm{mV}$ from a nerve-bouton preparation of a 9-d-old rat were completely (but reversibly) blocked by $10 \mu \mathrm{m}$ bicuculline. $B$, Parts of trace $A$ on expanded time scale. $C$, In the presence of $100 \mu \mathrm{m} \mathrm{APV}$ and $20 \mu \mathrm{M} \mathrm{DNQX}$, recordings from a VTADA neuron in the brain slice of a 10-d-old rat show spontaneous IPSCS at various levels of $V_{\mathrm{H}} \cdot D, I-V$ plot of mean ( \pm SEM) data from four neurons and line of best fit (linear regression). $E$, Superimposed current traces (each an average of 6 evoked IPSCS) were obtained from a brain slice of a $10-d$-old rat before and after addition of bicuculline (at a $V_{H}$ of $-60 \mathrm{mV}$ ). In these and other figures, the initial stimulus artifacts are truncated.

illumination, cell bodies of VTA neurons were readily visible in these slices, which contain a substantial part of the GABAergic projections from the nucleus accumbens and ventral pallidum as well as intrinsic GABAergic interneurons (Mansvelder et al., 2002). Many spontaneous responses were obtained from the mechanically dissociated neurons with adherent synaptic terminals (nerve-bouton preparations), which provide good conditions for space-clamp recording without interference from other neurons or glia (Akaike and Moorhouse, 2003).

\section{Electrophysiological properties of VTA DA and GABAergic neurons}

As illustrated in Figure $1 B$, most putative DA neurons fired spontaneously in a regular pacemaker manner. Between -70 and $-130 \mathrm{mV}$, the input resistance (measured with hyperpolarizing currents as in Fig. $1 D)$ was $175 \pm 40 \mathrm{M} \Omega(n=6)$, in agreement with previous studies of DA neurons (Grace, 1988; Mercuri et al., 1990). A prominent hyperpolarization-activated inward current $\left(I_{\mathrm{h}}\right)$ confirmed the identity of the DA neurons (Fig. 1D) (Johnson 

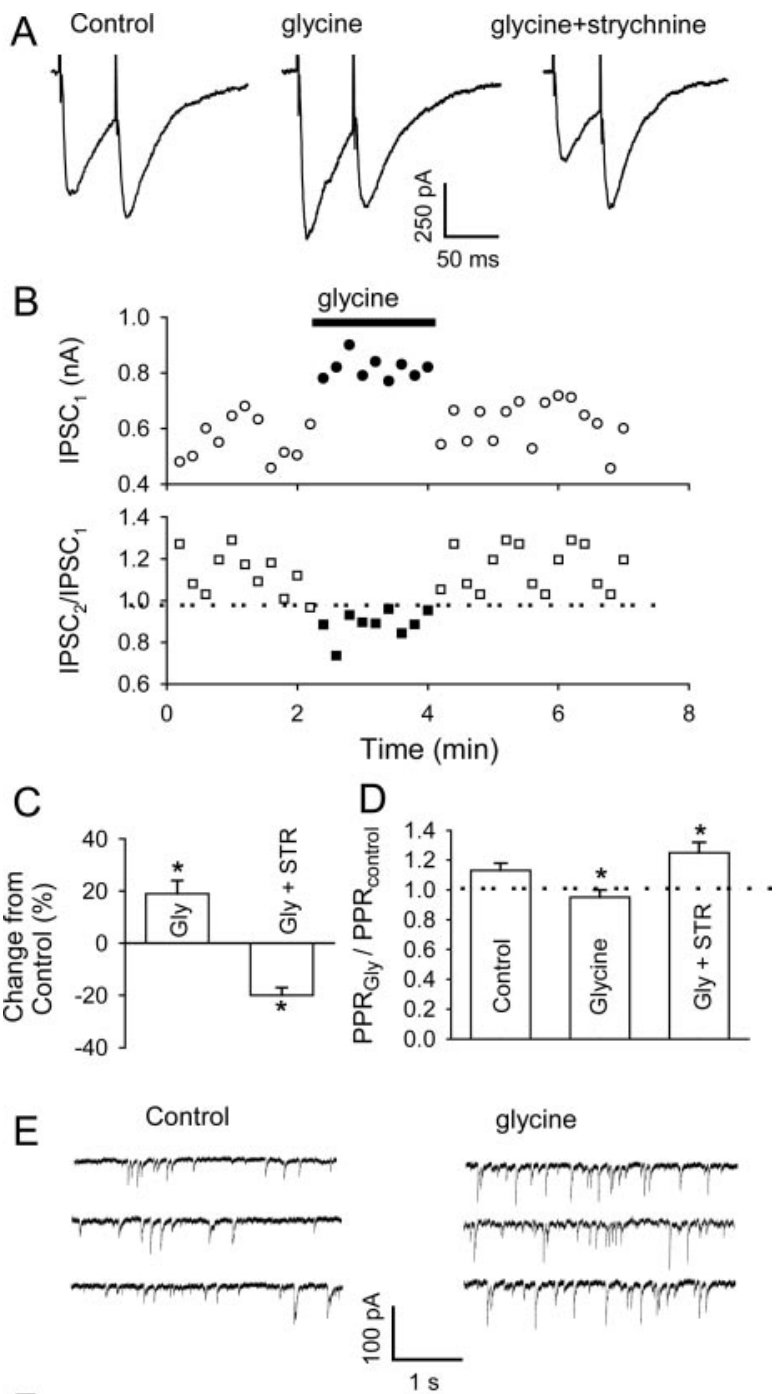

$\mathrm{F}$
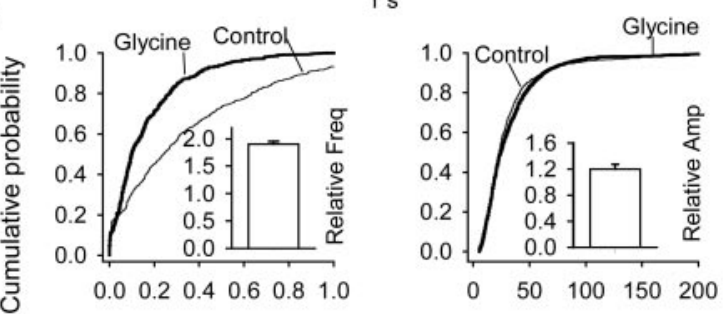

Interevent Interval (s)

Amplitude (pA)

Figure 3. Glycine potentiates IPSCs in midbrain slices. A, GABAergic elPSCs evoked in DA neuron with paired pulses (at $60 \mathrm{msec}$ interval) in control conditions (left trace), in the presence of $3 \mu \mathrm{m}$ glycine (middle trace), and after adding $1 \mu \mathrm{m}$ strychnine (trace at right). Glycine enhanced the first eIPSC, and its effect was blocked by strychnine. Data are averages of 10 traces, all recorded at a $V_{\mathrm{H}}$ of $-60 \mathrm{mV}$ from the same neuron in VTA slice of a 10-d-old rat. $B$, Time course of the glycine-induced enhancement of IPSC ${ }_{1}$ (circles) and depression of pairedpulse facilitation (squares) observed in one experiment, where IPSC $C_{1}$ and IPSC $C_{2}$ are the peak responses to the first and second stimulus. C, Summary of data from five neurons in slices.

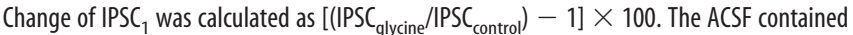
DNQX $(20 \mu \mathrm{M})$ and APV $(100 \mu \mathrm{m}) . D$, Effects of glycine and glycine plus strychnine on PPR $(p<$ $0.05 ; n=4)$. Asterisks indicate $p<0.05$. Note that strychnine not only blocked the effect of glycine but reduced elPSC 1 and increased PPR. This suggests that presynaptic GlyRs were activated by ongoing release of GlyR ligand(s) (Fig. 9). E, Spontaneous IPSCs recorded from a DA neuron in brain slice before (control) and during the application of $3 \mu \mathrm{m}$ glycine. F, Cumulative probability plots for sIPSC inter-event intervals (left; K-S test, $p<0.001$; glycine vs control) and amplitudes (right; $p>0.5$ ) in same experiment. The number of events used for cumulative distributions was 349 for control and 692 for glycine during 2 min. Inset, Pooled data from five cells show that glycine increased sIPSC frequency but not amplitude. and North, 1992). In contrast, the non-DA neurons fired irregularly (Fig. $1 F)$, had a higher input resistance $(923 \pm 100 \mathrm{M} \Omega ; n=$ $7)$, a more negative resting potential $(-69.5 \pm 5.3 \mathrm{mV}, n=5$, compared with $-53.7 \pm 4.6 \mathrm{mV}, n=7$; $p<0.01$ for DA neurons), shorter spikes ( $1.5 \pm 0.5 \mathrm{msec}, n=10$, compared with $4.0 \pm 0.5 \mathrm{msec}, n=30 ; p<0.01$ for DA neurons), and no $I_{\mathrm{h}}$ (Fig. $1 E)$. Most of the $I_{\mathrm{h}}$-negative neurons in the VTA are GABAergic (Grace and Onn, 1989; Steffensen et al., 1998). The following experiments focused on DA neurons, identified by a prominent $I_{\mathrm{h}}$ immediately after break in (Fig. $\left.1 D\right)$.

\section{Spontaneous GABAergic IPSCs recorded in dissociated DA neurons}

The whole-cell recordings from mechanically dissociated VTA neurons, at a holding potential $\left(V_{\mathrm{H}}\right)$ of $-50 \mathrm{mV}$, were made in the presence of APV $(50 \mu \mathrm{M})$ and CNQX $(10 \mu \mathrm{M})$ to eliminate NMDA receptor- and AMPA receptor-mediated synaptic currents. As reported by Bonci and Williams (1997) this "blocker cocktail" did not affect the holding current of the DA cells. In 30 of 35 cells tested, bicuculline $(10 \mu \mathrm{M})$ reversibly abolished the spontaneous discharge of IPSCs (Fig. $2 A, B$ ). The bicucullineresistant sIPSCs, which remained in five cells, were readily blocked by $1 \mu \mathrm{M}$ strychnine. In older rats, bicuculline $(10 \mu \mathrm{M})$ reversibly abolished the sIPSCs in 17 of 20 cells tested. Strychnine $(1 \mu \mathrm{M})$ eliminated the bicuculline-resistant sIPSCs remaining in three cells (data not shown). Thus, a subset of VTA DA neurons appears to receive a functional glycinergic innervation. From recordings at various values of $V_{\mathrm{H}}$ and the corresponding $I-V$ relationships (Fig. $2 C, D$ ), the reversal potential of the sIPSCs was -5 $\mathrm{mV}(n=4)$, very close to the theoretical $\mathrm{Cl}^{-}$equilibrium potential $\left(E_{\mathrm{Cl}}\right),-1.4 \mathrm{mV}$, calculated by the Nernst equation for extracellular and intracellular $\mathrm{Cl}^{-}$concentrations of 151 and $143 \mathrm{~mm}$, respectively. In these dissociated DA neurons, sIPSCs originate predominantly from GABAergic synapses as well as a few glycinergic synapses.

\section{Glycine potentiates GABAergic eIPSCs}

In 8 of 10 cells tested, bicuculline $(10 \mu \mathrm{M})$ also abolished the postsynaptic currents (eIPSCs) recorded in midbrain slices in the presence of $100 \mu \mathrm{M}$ APV and $20 \mu \mathrm{M}$ CNQX (Fig. $2 E$ ) [in the other two cells, strychnine $(1 \mu \mathrm{M})$ fully blocked the remaining eIPSCs]. The GABAergic eIPSCs were significantly enhanced by $3 \mu \mathrm{M}$ glycine, as illustrated by the traces in Figure $3 A$, where the first of each pair of eIPSCs increased by $40 \%$ and the effect of glycine was suppressed by adding $1 \mu \mathrm{M}$ strychnine. Overall, eIPSCs increased by $33 \pm 5 \%(n=7 ; p<0.05)$ (Fig. $3 C)$, but they returned to their control size after washout of glycine (Fig. $3 B$ ). The consistent block by strychnine (Fig. $3 A, C$ ) indicates that glycine acted via conventional GlyRs.

The action of glycine could be at a postsynaptic or presynaptic site. It cannot be ascribed to a postsynaptic change in $\mathrm{Cl}^{-}$gradient, because control and potentiated IPSCs did not differ significantly in their reversal potentials: $-5.2 \pm 2.5 \mathrm{mV}(n=4)$ in control versus $-4.8 \pm 2.3 \mathrm{mV}(n=4)$ in $3 \mu \mathrm{M}$ glycine $(p>0.05)$. Two kinds of observations (in slices) point to a presynaptic effect: an increase in GABA release. First, when pairs of IPSCs were evoked (at an interval of $60 \mathrm{msec}$, as in Fig. 3A), glycine selectively enhanced the first IPSC (IPSC 1 ) but not the second (IPSC 2 ), thus suppressing paired-pulse facilitation (PPF). The paired-pulse ratio $(\mathrm{PPR})\left(\mathrm{PPR}=\mathrm{IPSC}_{2} / \mathrm{IPSC}_{1}\right)$ diminished from $1.13 \pm 0.05$ in five cells under control conditions to $0.95 \pm 0.05$ in the presence of $3 \mu \mathrm{M}$ glycine; in two of these cells, the initial PPF was converted to depression (Fig. 3A). This reversible change in PPF (Fig. 3B) 
A

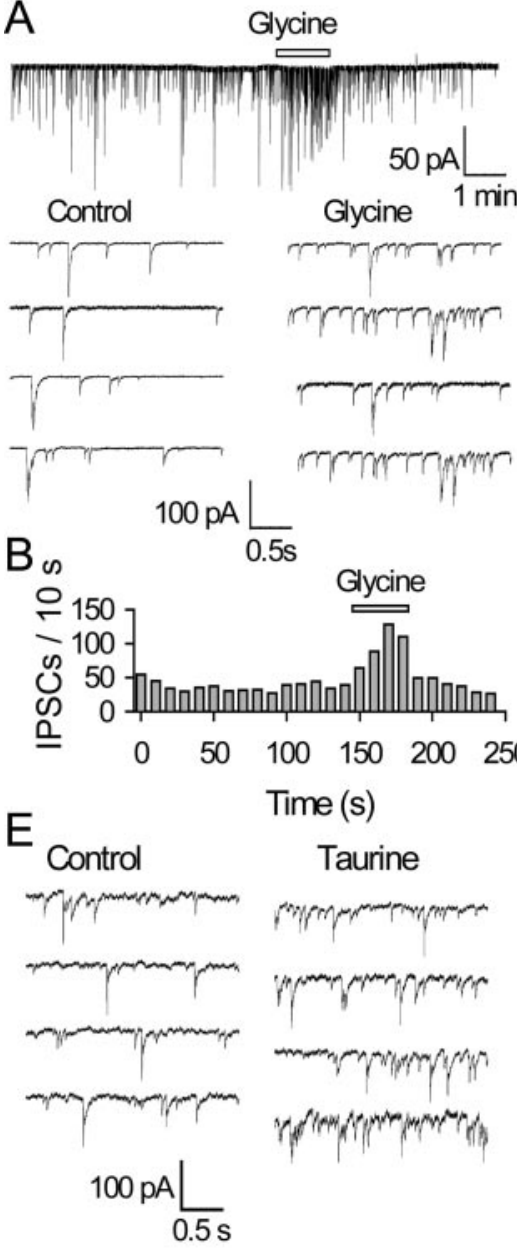

$\mathrm{F}$

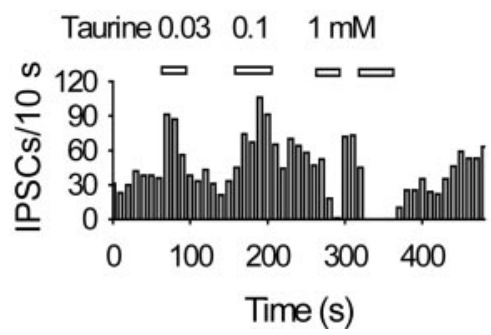

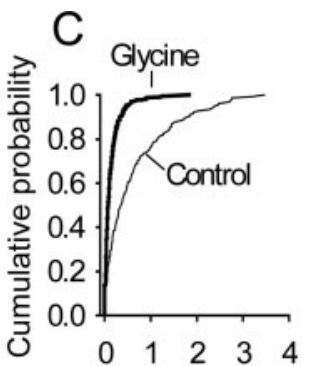

Interevent Interval (s)

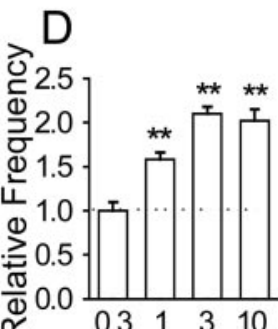

[Glycine] (microM)
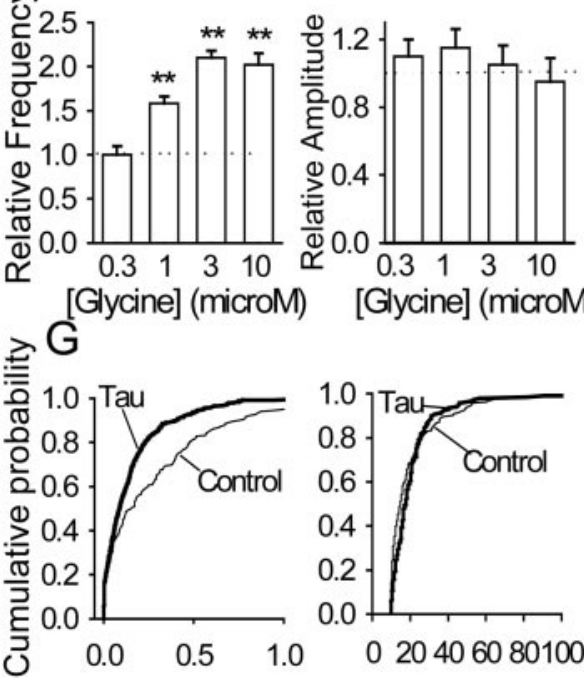

[Glycine] (microM)

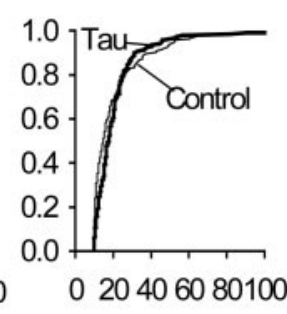

Interevent interval (s)

Amplitude ( $\mathrm{pA})$

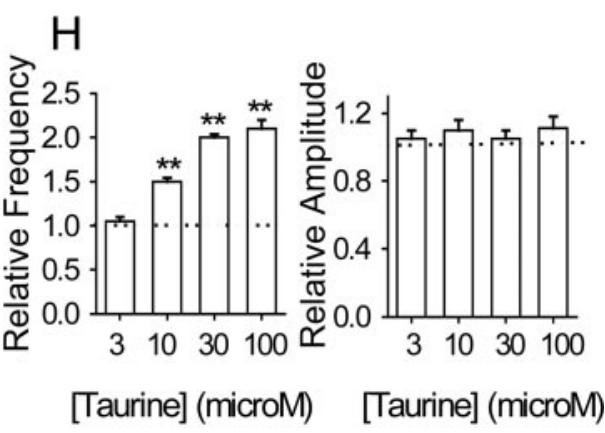

Figure 4. Glycine and taurine act at a presynaptic locus: data from nerve-bouton preparations. A, GABAergic sIPSCs recorded before, during, and after the application of $1 \mu \mathrm{m}$ glycine; some accelerated traces are shown. $B$, Time course of glycine-induced enhancement of sIPSC frequency ( $A$, top trace). C, For same data, cumulative probability plots of sIPSC interevent intervals (left; K-S test, $p<0.001$ ) and amplitudes (right; $p>0.5$, glycine vs control). The number of events used for cumulative distributions was 240 for control and 610 for glycine during $1 \mathrm{~min}$. D, Relative frequency and amplitude of sIPSCs as function of glycine concentration; before pooling ( $n=4-6)$, all data were normalized to the values obtained in the absence of glycine. $E$, Traces of sIPSCs obtained in the absence and presence of $30 \mu \mathrm{m}$ taurine. $F$, Time course of changes in sIPSC frequency (in 1 cell): note that the frequency was raised by 30 and $100 \mu \mathrm{m}$ taurine, but sIPSCs were eliminated by $1 \mathrm{~mm}$ taurine. $G$, For same data, cumulative probability plots of sIPSC interevent intervals (left; K-S test, $p<0.001$ ) and amplitudes (right; $p>0.5$, taurine vs control). The number of events used for cumulative distributions was 254 for control and 638 for taurine during $1 \mathrm{~min}$. $H$, Relative frequency and amplitude of SIPSCS as function of taurine concentration $\left(n=3-5 ;{ }^{* *} p<0.01\right)$.

was prevented by strychnine (Fig. $3 A, D$ ). Manipulations that increase transmitter release generally result in a shift of PPF toward depression (Mennerick and Zorumski, 1995; Salin et al., 1996; Bonci and Williams, 1997). According to these results, glycine enhances the probability of synaptic GABA release, presumably by depolarizing the GABAergic terminals. This suggests that the glycine reversal potential is relatively positive for these termi- nals as it is for postsynaptic neurons $(-29$ $\mathrm{mV}$ for intact cells at this stage of development) (Ye, 2000).

\section{Glycine and taurine raise the frequency} of sIPSCs

A second set of observations also indicated a presynaptic site of glycine action. In slices, $3 \mu \mathrm{M}$ glycine sharply increased the frequency of sIPSCs (Fig. 3E) but did not significantly change their amplitude. The increase in sIPSC frequency (by $85 \pm 5 \% ; p<$ $0.01 ; n=5$ ) is further illustrated in Figure $3 F$, left, by the leftward shift of cumulative plots of the distribution of intervals between successive sIPSCs and the accompanying histogram. The corresponding plots in Figure 3F, right, illustrate the lack of change in amplitude (14 $\pm 8 \% ; p>0.05 ; n=5)$. Similar results were obtained from mechanically isolated VTA cells: $1 \mu \mathrm{m}$ glycine raised the sIPSC frequency by $68 \pm 8 \%(p<0.01 ; n=$ $4)$, but their amplitude was unaltered (11 \pm $6 \% ; p>0.05 ; n=4$ ) (Fig. $4 A-C$ ). The histograms in Figure $4 D$ summarize the concentration dependence of the action of glycine: 1 and $3 \mu \mathrm{M}$ glycine raised the sIPSC frequency to $168 \pm 8$ and $189 \pm 8 \%$ of control, respectively (in both cases, $n=4$ and $p<0.01$ ), without any change in amplitude. In most cells, such concentrations of glycine induced minimal or no postsynaptic current (Figs. $4 A, 5 A, 6 A a, 8 C a, 10 D$ ). At $10 \mu \mathrm{M}$, glycine evoked a small postsynaptic current but no further increase in sIPSC frequency (to $179 \pm 13 \%$ of control; $n=6$ ). With even higher concentrations of glycine ( $30 \mu \mathrm{M}$ and above), the large postsynaptic $\mathrm{Cl}^{-}$conductance increase shunted the sIPSCs.

In the presence of strychnine $(0.5 \mu \mathrm{M})$, glycine $(1 \mu \mathrm{M})$ was much less effective: the frequency of sIPSCs rose by only $15 \pm 5 \%$ (cf. $60 \pm 6 \%$ in control tests on the same cells; $p<0.05 ; n=3$ ). This was probably not caused by a run-down of the action of glycine; after strychnine washout, glycine again markedly increased the frequency of sIPSCs (data not shown). Bicuculline (10 $\mu \mathrm{M})$ eliminated all sIPSCs both in the absence and presence of glycine (data not shown), confirming that the observed sIPSCs were indeed GABAergic. Similar results were obtained from six other neurons. Together, these results suggest that glycine, acting via GlyRs on or near GABAergic terminals, enhances the probability of spontaneous GABA release.

Taurine is a full agonist of GlyRs in many areas of the brain, including the nucleus accumbens (Jiang et al., 2004) and VTA (Wang and Ye, 2003). As therefore expected, low concentrations of taurine $(10-100 \mu \mathrm{M})$ sharply raised the frequency of sIPSCs (30 $\mu \mathrm{M}$ taurine to $195 \pm 5 \%$ of control; $n=5 ; p<0.01$ ) without affecting their amplitude (which remained at $105 \pm 5 \%$ of con- 
trol; $n=5 ; p=0.62$ ) (Fig. $4 E-G$ ), but 100 $\mu \mathrm{M}$ taurine evoked a small postsynaptic current, no significant further increase in frequency $(211 \pm 10$ of control; $n=3 ; p<$ 0.01 ), and no change in amplitude (Fig. $4 F, H)$. With even higher concentrations of taurine (300 $\mu \mathrm{M}$ and above), a large postsynaptic current shunted the sIPSCs (data not shown). The effect of taurine was blocked by strychnine (mean sIPSC frequency, $4.6 \mathrm{sec}^{-1}$ in control, $4.9 \mathrm{sec}^{-1}$ in $30 \mu \mathrm{M}$ taurine plus $0.5 \mu \mathrm{M}$ strychnine; $n=$ $3 ; p=0.3)$ (data not shown). These results confirm the glycinomimetic properties of taurine in the VTA. They are of more than secondary significance because taurine is both present in the brain and released in large amounts in the early postnatal period and therefore could be a major agonist at GlyRs during this phase of development (see Discussion).

\section{Glycine acts in a TTX-and \\ $\mathrm{Ca}^{2+}$-sensitive manner}

We next investigated whether TTXsensitive $\mathrm{Na}^{+}$channels are involved in the glycine-induced facilitation of sIPSCs (Jeong et al., 2003). In five of eight nervebouton preparations, TTX (300 nM) sharply decreased sIPSC frequency to $41 \pm$ $3 \%$ of control (from $6.2 \pm 1.5$ to $2.7 \pm 0.3$ $\left.\sec ^{-1} ; n=5 ; p<0.01\right)$ and moderately reduced the amplitude to $75 \pm 8 \%$ of control (from $26 \pm 5$ to $20 \pm 1 \mathrm{pA} ; p<0.05$ ) (Fig. $5 A, B a, b$ ). In these five cells, the mIPSCs remaining in the presence of TTX were quite insensitive to $3 \mu \mathrm{M}$ glycine, which had no significant effect on either their frequency (to $105 \pm 25 \%$ of control; $p>0.5 ; n=5$ ) or their amplitude (to $95 \pm$ $8 \%$ of control; $p>0.5$ ) (Fig. $5 C c, d$ ). The sIPSCs and the potentiation by glycine soon returned after washout of TTX (Fig. $5 A, B d, D)$. Nevertheless, in the other three isolated cells, glycine elicited a similar $\sim 40 \%$ increase in IPSC frequency in the absence and presence of $300 \mathrm{~nm}$ TTX; the changes were $2.2-3.1 \mathrm{sec}^{-1}$ before and $1.9-2.6 \mathrm{sec}^{-1}$ (K-S test; $\left.p<0.0001\right)$ after the application of TTX. These results suggest that in many terminals, the $\mathrm{Cl}^{-}$effluxmediated depolarizing action is too weak to initiate GABA release without the assistance of TTX-sensitive $\mathrm{Na}^{+}$channels in partial agreement with recent findings in the spinal cord (Jeong et al., 2003).

To determine whether the action of glycine requires $\mathrm{Ca}^{2+}$ influx, we first reduced extracellular $\left[\mathrm{Ca}^{2+}\right]$. In nerve-bouton preparations kept in external solution containing $1.0 \mathrm{mM}\left[\mathrm{Ca}^{2+}\right]$ (instead of the standard $2.0 \mathrm{~mm}$ ), sIPSC frequency was reduced to $49 \pm 4.8 \%$ of control $(n=4 ; p<0.01)$, and in $\mathrm{Ca}^{2+}$-free external solution, sIPSCs virtually disappeared (to $6.5 \pm 5.5 \% ; n=3$ ) (Fig. $6 A b, B$ ). Any remaining IPSCs are likely to be mIPSCs, which are typically insensitive to external $\mathrm{Ca}^{2+}$ (Liley, 1956; Thompson et al., 1993; Druzin et al., 2002). In the absence of
$\mathrm{Ca}^{2+}$, glycine $(3 \mu \mathrm{M})$ failed to increase significantly the frequency of the few remaining sIPSCs, which stayed at $120 \pm 8 \%$ of the $\mathrm{Ca}^{2+}$-free control value $(n=3 ; p=0.5)$ (Fig. $\left.6 A b, B\right)$. When $\mathrm{Cd}^{2+}(50 \mu \mathrm{M})$, a nonselective blocker of voltage-dependent $\mathrm{Ca}^{2+}$ channels, was applied to the isolated neurons, all of the larger sIPSCs disappeared (Fig. 6Ac). The remaining sIPSCs had amplitudes of $8.2 \pm 0.7 \mathrm{pA}(n=3)$, and their frequency was reduced to $4.3 \pm 4.5 \%$ of control $(n=5 ; p<0.01)$ (Fig. $6 B)$. In the continued presence of $\mathrm{Cd}^{2+}$, glycine did not change the frequency $(96.3 \pm 5.2 \% ; n=4 ; p=0.4$ ) (Fig. 6Ac,B). Judging by these results, the ongoing generation of sIPSCs in isolated cells is primarily dependent on the activation of both $\mathrm{Na}^{+}$and $\mathrm{Ca}^{2+}$ channels.

In slices, $100 \mu \mathrm{M} \mathrm{Cd}^{2+}$ reduced the amplitude of sIPSCs by $61 \%$, from $95.9 \pm 2.2$ to $37.5 \pm 1.6 \mathrm{pA}$, and their frequency by 
A

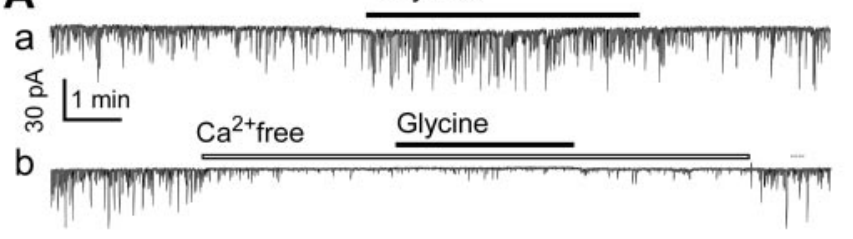

c
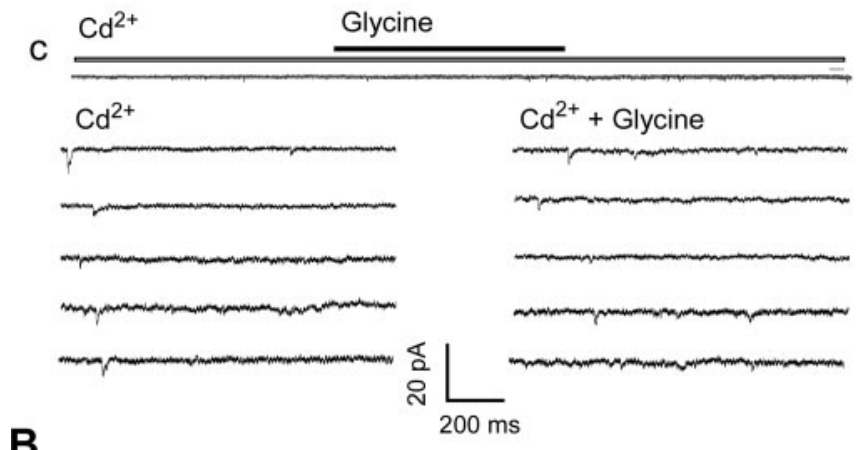

B
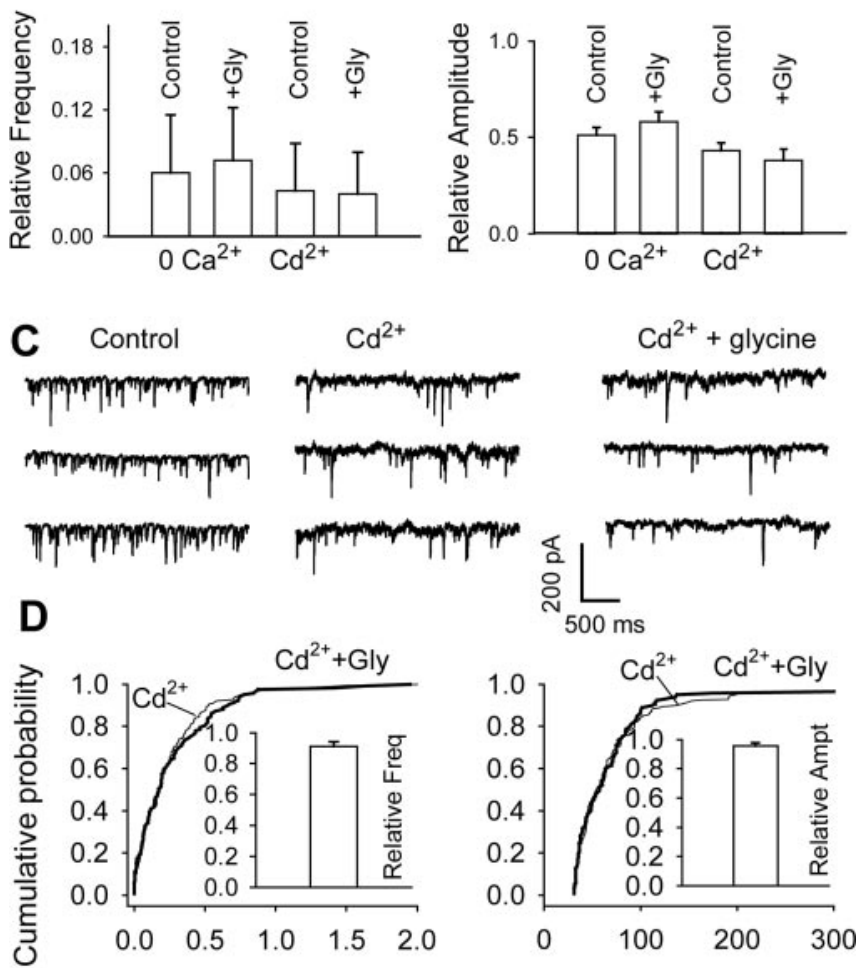

Interevent Intervals (s)
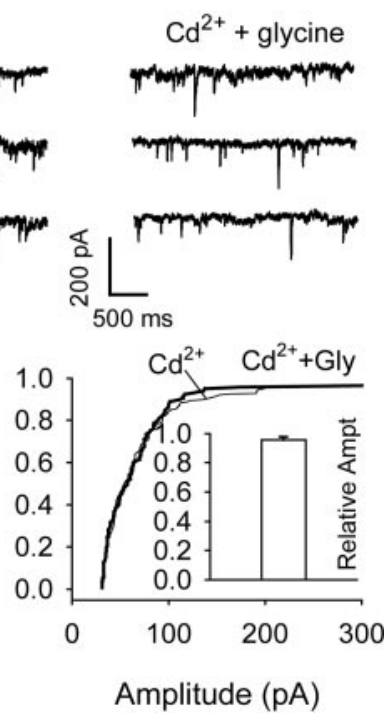

Figure 6. The action of glycine involves $\mathrm{Ca}^{2+}$ channels: data from DA neurons in nervebouton preparations $(A, B)$ and slices $(C, D)$. A, GABAergic sIPSCs recorded from an isolated neuron before, during, and after the application of $3 \mu \mathrm{m}$ glycine in standard medium $(a)$, $\mathrm{Ca}^{2+}$-free solution $(b)$, and the presence of $50 \mu \mathrm{M} \mathrm{Cd}^{2+}(c)$. Horizontal bars indicate applications of glycine, $\mathrm{Ca}^{2+}$-free medium, and $\mathrm{Cd}^{2+}$. Note that the presence of $\mathrm{Cd}^{2+}$ and lack of $\mathrm{Ca}^{2+}$ suppress most sIPSCS. Bottom, Several traces illustrate sIPSCs from trace $A$ c on expanded time scale and at higher gain. $B$, Pooled data (means $\pm S E M ; n=3-5$ ) show minimal effects of glycine on sIPSC frequency (left) and amplitude (right) in medium containing no $\mathrm{Ca}^{2+}$ or $50 \mu \mathrm{M}$ $\mathrm{Cd}^{2+}$. These data were normalized to the values recorded in standard medium (with $\left.2 \mathrm{mM} \mathrm{Ca}^{2+}\right) . C$, sIPSCs recorded in midbrain slice in standard ACSF (left), in the presence of 100 $\mu \mathrm{M} \mathrm{Cd}^{2+}$ (center), and in $100 \mu \mathrm{M} \mathrm{Cd}^{2+}$ plus $3 \mu \mathrm{m}$ glycine (right). The number of events used for cumulative distributions was 212 for $\mathrm{Cd}^{2+}$ and 230 for glycine during $3 \mathrm{~min}$. D, Cumulative probability plots of data from the same cell. Pooled data inset in $D$ (means $\pm S E M ; n=3$ ) show minimal effects of glycine on sIPSC frequency (left) and amplitude (right) in presence of 100 $\mathrm{Cd}^{2+}$ or $100 \mu \mathrm{m} \mathrm{Cd}^{2+}$ plus $3 \mu \mathrm{m}$ glycine. These data were normalized to the values recorded in $100 \mu \mathrm{M} C d^{2+}$.
$65 \%$, from $21.3 \mathrm{sec}^{-1}$ to $7.4 \mathrm{sec}^{-1}$ (Fig. 6C), and also greatly reduced eIPSCs (by 95\%, from $764.8 \pm 71.5$ to $40.6 \pm 14.5 \mathrm{pA}$; $n=4)$. Furthermore, $100 \mu \mathrm{M} \mathrm{Cd}^{2+}$ eliminated the effect of glycine on sIPSCs. In the presence of $\mathrm{Cd}^{2+}$, glycine had no significant effect on the frequency $\left(3.64 \pm 0.2 \mathrm{sec}^{-1}\right.$ in glycine vs $3.99 \pm$ $0.4 \mathrm{sec}^{-1}$ in control) or amplitude of sIPSCs $(72.9 \pm 5.7 \mathrm{pA}$ in glycine vs $76.2 \pm 4.7 \mathrm{pA}$ in control) (Fig. 6C). This was also reflected in the cumulative probability histograms (Fig. 6D). According to pooled data from three cells, the frequency and amplitude remained at $91 \pm 2$ and $96 \pm 2 \%$, respectively $(p>0.5$ ) (Fig. $6 D$, insets). In six slices, $\mathrm{Cd}^{2+}$ eliminated the action of glycine on eIPSCs (data not shown).

Glycine raises the $\mathrm{Ca}^{2+}$ concentration $\left(\left[\mathrm{Ca}^{2+}\right]\right)$ in presynaptic terminals

We next measured changes of $\left[\mathrm{Ca}^{2+}\right]$ in presynaptic terminals of mechanically dissociated neurons using the $\mathrm{Ca}^{2+}$-sensitive dye fura-2. To eliminate potential interference by changes in postsynaptic $\left[\mathrm{Ca}^{2+}\right]$, individual fura-2-loaded neurons were voltage clamped at $-60 \mathrm{mV}$ with a pipette containing the following (in $\mathrm{mm}$ ): $140 \mathrm{CsF}, 1.0 \mathrm{MgCl}_{2}, 10 \mathrm{HEPES}, 11$ EGTA, and 2 TEA (tetraethylammonium chloride), $\mathrm{pH} 7.3$ (adjusted with $\mathrm{CsOH}$ ) and $300 \mathrm{mOsm}$. Approximately $10 \mathrm{~min}$ were allowed for the pipette solution to completely dialyze the postsynaptic neurons. In most cases, this eliminated or drastically reduced fura-2 fluorescence in the cell body $(n=45)$ (Fig. 7A). A few discrete fura-2-labeled spots were clearly visible on the surface of $\sim 30 \%$ of the cells, indicating the presence of presynaptic boutons (Fig. $7 B$, top left). This was confirmed by overlapping staining with FM1-43 at the end of the experiment (Fig. 7B, top right). Approximately $70 \%$ of neurons did not show clear fura-2-loaded spots after whole-cell dialysis, perhaps because of the lack of attached boutons, or because some boutons failed to retain fura- 2 .

After recording a stable baseline of $340 / 380$ ratio images, we applied glycine $(100 \mu \mathrm{M})$ to the neuron. This led to a moderate but significant increase in 340/380 ratio, by $22.1 \pm 9.6 \%(n=13$; $p<0.05$ ) (Fig. $7 B, C$ ), indicating a rise in intraterminal free $\left[\mathrm{Ca}^{2+}\right]$. At a lower concentration $(10 \mu \mathrm{M})$, glycine elicited a smaller but significant increase of the $340 / 380$ ratio, by $6.9 \pm$ $2.0 \%(n=5 ; p<0.05)$ (data not shown). The block of these effects by strychnine $(1 \mu \mathrm{M})$ showed that they were mediated by conventional GlyRs (in the presence of strychnine, the 340/380 ratio changed by only $2.0 \pm 0.9 \% ; n=5 ; p>0.05$ ) (Fig. $7 B, C$ ). Direct membrane depolarization by $45 \mathrm{~mm}\left[\mathrm{~K}^{+}\right]$also raised intraterminal $\left[\mathrm{Ca}^{2+}\right]$ (the $340 / 380$ ratio increased by $24.8 \pm 10.7 \%$; $n=9 ; p<0.05$ ) (Fig. $7 B, C)$.

\section{Involvement of $\mathrm{N}$ - or $\mathrm{P} / \mathrm{Q}$-type $\mathrm{Ca}^{2+}$ channels in} glycine-induced increase of intraterminal $\left[\mathrm{Ca}^{2+}\right]$ A key step in neurotransmitter release is the entry of $\mathrm{Ca}^{2+}$ into the presynaptic terminal, predominantly via $\mathrm{N}$ - and $\mathrm{P} / \mathrm{Q}$-type $\mathrm{Ca}^{2+}$ channels (Reid et al., 2003). To determine whether these channels were involved, we applied glycine in the presence of $\omega$-conotoxin MVIIA. At a high concentration (e.g., $3 \mu \mathrm{M}$ ), this toxin nonspecifically blocks L-, N-, and P/Q-type $\mathrm{Ca}^{2+}$ channels (Feng et al., 2003). As shown in Figure 7, $B$ and $C, 3 \mu \mathrm{M}$ $\omega$-conotoxin MVIIA sharply reduced the rise in $\left[\mathrm{Ca}^{2+}\right]_{\mathrm{i}}$ elicited by glycine (the $340 / 380$ ratio increased by only $3.5 \pm 1.3 \% ; n=6$; $p>0.05)$. In contrast, the L-type $\mathrm{Ca}^{2+}$ channel blocker nimodipine $(5 \mu \mathrm{M})$ was ineffective (glycine increased the $340 / 380$ ratio by $19.8 \pm 5.7 \% ; n=3 ; p<0.05)$.

These data strongly suggest that activation of $\mathrm{N}$ - and/or P/Qtype $\mathrm{Ca}^{2+}$ channels and subsequent $\mathrm{Ca}^{2+}$ entry are primarily 
responsible for the glycine-induced increase in transmitter release.

The presynaptic GlyRs are

tonically activated

Tonic activation of neurotransmitter receptors in brain slices has been demonstrated for both $\mathrm{GABA}_{\mathrm{A}}$ receptors (LoTurco et al., 1995; Brickley et al., 1996; Yeung et al., 2003; Semyanov et al., 2004) and GlyRs (Flint et al., 1998). We have evidence that GlyRs on VTA DA neurons are also tonically activated. In slices, $1 \mu \mathrm{M}$ strychnine reduced the amplitude of eIPSCs to $88 \pm 2 \%(n=5 ; p<0.05)$ of control and thus increased PPF from $13 \pm$ 3 to $30 \pm 4 \%(p<0.05 ; n=5)$ (Fig. $8 A, B)$. Furthermore, strychnine lowered the frequency of sIPSCs in nerve-bouton preparations by $40 \pm 5 \%(n=4 ; p<0.01)$ without affecting their amplitude (this remained at $98 \pm 8 \%$ of control; $p=0.9$ ) (Fig. $8 C-F$ ). The reduction in mean frequency was also reflected in the cumulative frequency distributions, shifting that of sIPSC interevent intervals to the right without affecting the distribution of sIPSC amplitudes. As illustrated in Figure 8C, 10 $\mu \mathrm{M}$ bicuculline eliminated all sIPSCs, so glycinergic IPSCs could not have contributed to the sIPSCs suppressed by strychnine. In three other isolated cells, strychnine $(0.1-1 \mu \mathrm{M})$ induced a small outward current and lowered both the frequency and the amplitude of the sIPSCs (data not shown).

Comparable results were obtained in slices kept at $33^{\circ} \mathrm{C}$, where glycine uptake is more active. Initially, PPF was absent $(8 \pm$ $10 \%$, where percentage of PPF is $100\left[\left(\right.\right.$ IPSC $_{2} /$ IPSC $\left.\left.\left._{1}\right)-1\right]\right)$, but when strychnine $(1 \mu \mathrm{M})$ was applied, PPF became clear $(25 \pm 9 \%$; $p<0.05 ; n=3)$. Moreover, at $33^{\circ} \mathrm{C}$, strychnine $(1 \mu \mathrm{M})$ reduced the frequency of sIPSCs from $4.5 \pm$ $0.8 \mathrm{sec}^{-1}$ to $2.8 \pm 0.5 \mathrm{sec}^{-1}(p<0.05 ; n=$ $3)$. All data are most readily explained by a tonic glycinergic action of ongoing glycine/taurine release that facilitates GABAergic transmission via presynaptic GlyRs.

In VTA from mature rats, the presynaptic action of glycine is reversed Our findings in neurons from young rats indicate that the presynaptic action of glycine enhances GABAergic transmission to VTA DA neurons. As the rats mature, the action of GABA changes from excitation to inhibition (Rivera et al., 1999). Thus, the question arose whether the presynaptic modulation of GABA synapses is restricted to the postnatal period or whether a com-
A

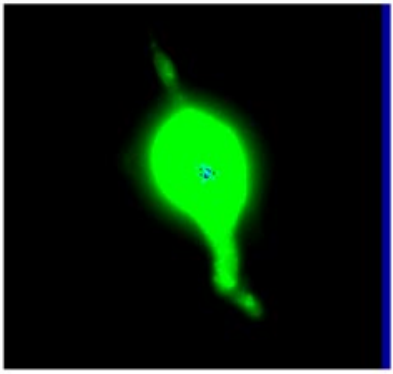
10 min after whole-cell

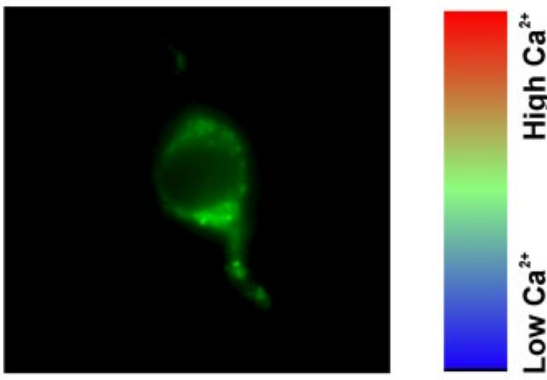

B
Control

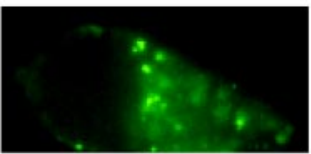

Glycine

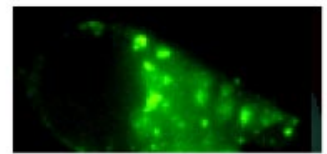

FM 1-43

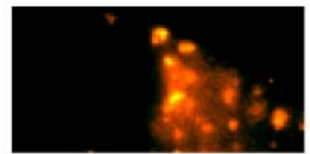

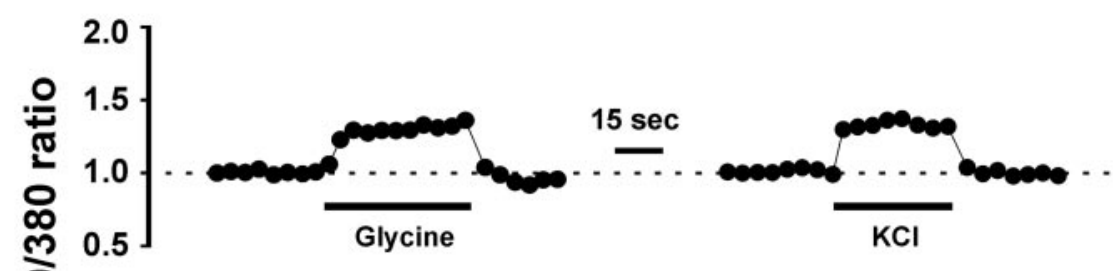

\}

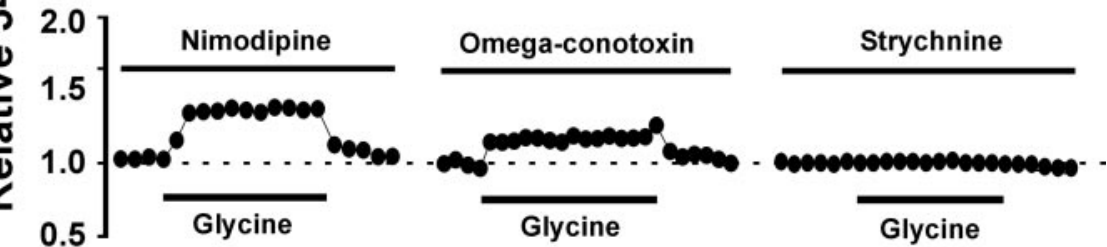

C

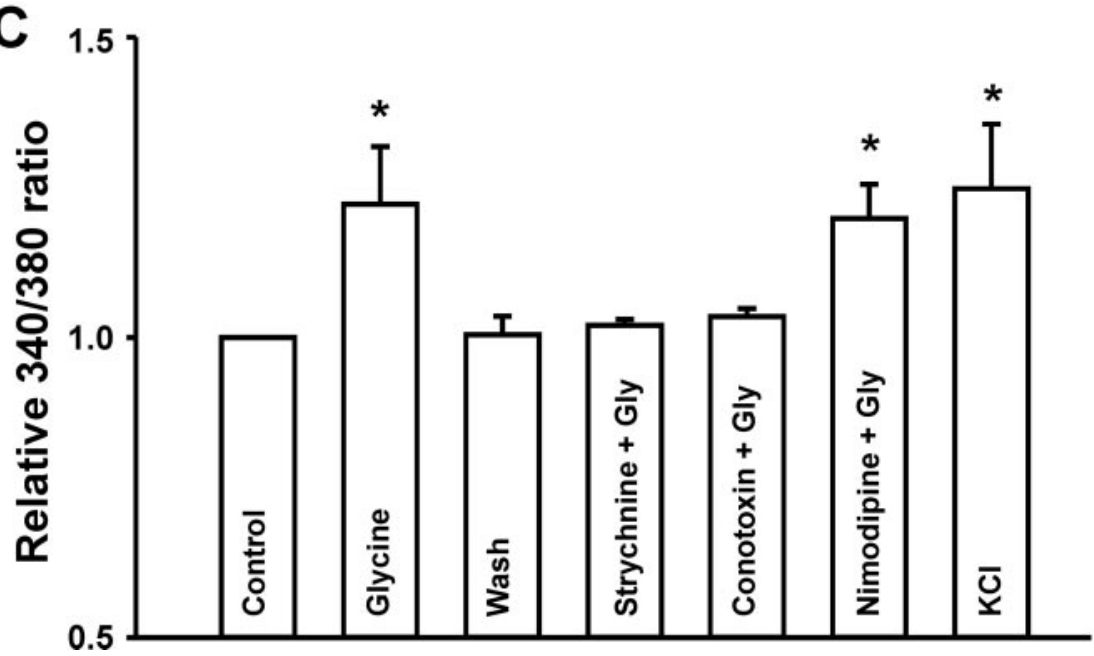

Figure 7. Glycine increases intracellular $\left[\mathrm{Ca}^{2+}\right]$ in presynaptic terminals on mechanically isolated DA neurons. A, Fura-2 fluorescence in cell body of a VTA neuron (left) has nearly disappeared after 10 min dialysis with CsF-containing pipette solution in whole-cell configuration (right). $B$, In top panels, presynaptic boutons are seen as fura-2-labeled spots (in 340 images); their intensities are increased by glycine $(100 \mu \mathrm{M})$, and they are also labeled by FM 1-43, a marker of synaptic vesicles (right). Plots of $340 / 380$ ratios in middle and bottom panels in $B$ further illustrate the increase of intraterminal $\left[\mathrm{Ca}^{2+}\right.$ ] elicited by glycine, which is mimicked by high $\mathrm{K}^{+}(45 \mathrm{~mm})$, much reduced by $3 \mu \mathrm{M} \omega$-conotoxin MVIIA (but not $5 \mu \mathrm{m}$ nimodipine) and eliminated by $1 \mu \mathrm{M}$ strychnine. C, Summary (means \pm SEM) of changes of $340 / 380$ ratios in presynaptic terminals produced by glycine $(n=13)$, strychnine plus glycine $(n=5)$, high $\mathrm{K}^{+}(n=9)$, $\omega$-conotoxin plus glycine $(n=6)$, and nimodipine plus glycine $(n=3) .{ }^{*} p<$ 0.05 . The increase of $340 / 380$ ratio was absent when glycine was applied in the presence of strychnine or $\omega$-conotoxin MVIIA. 


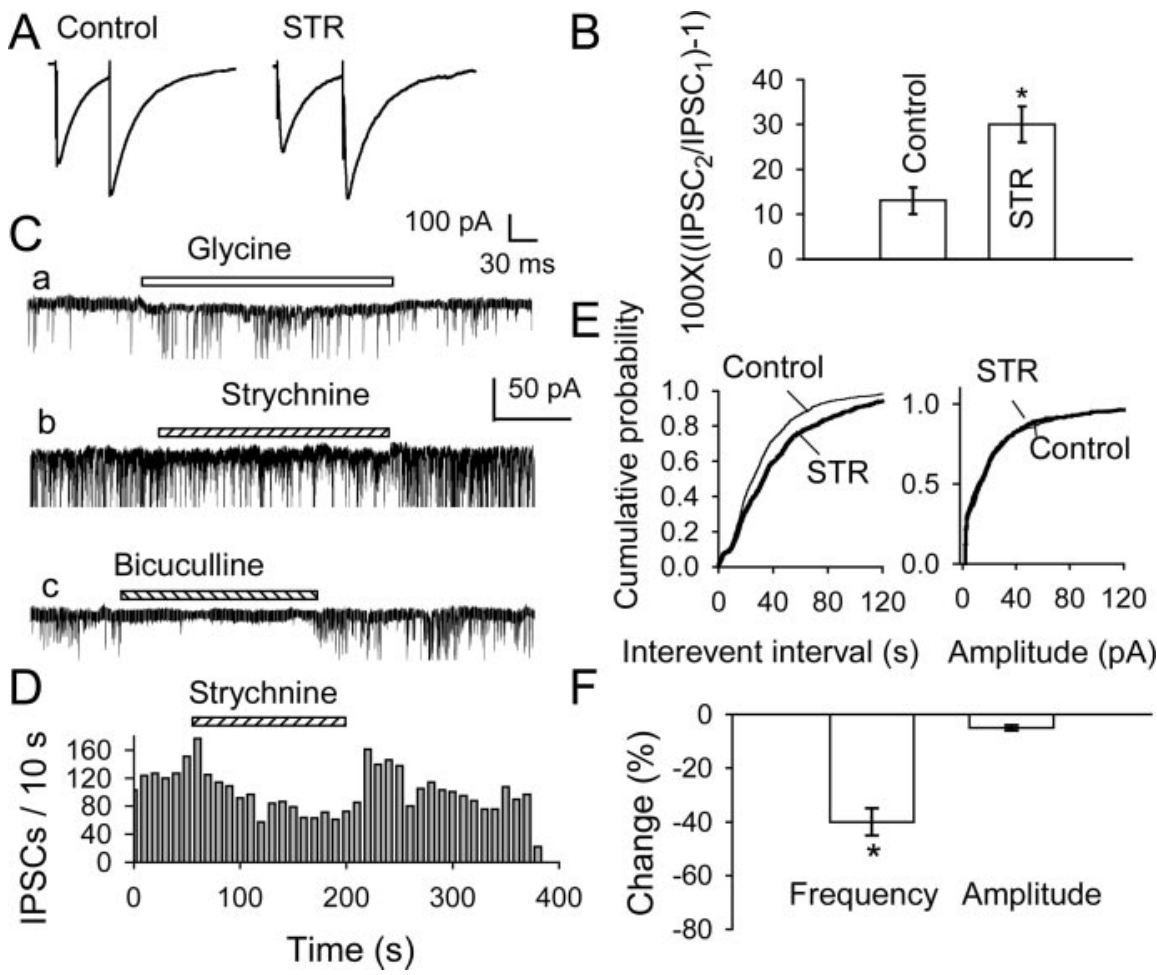

Figure 8. Strychnine depresses spontaneous and evoked IPSCs in VTA DA neurons from young (3-to 10-d-old) rats: data from slices $(A, B)$ and isolated nerve-bouton preparations $(C, D)$. $A$, Pairs of GABAergic elPSC elicited by paired-pulse stimulation (at 60 msec interval) in neuron in slice. By selectively depressing the first IPSC (eIPSC1), $1 \mu \mathrm{m}$ STR enhanced paired-pulse facilitation (illustrations are averages of 10 traces). B, Summary of percentage changes recorded in five neurons in slices. C, Frequency of sIPSCs in an isolated DA neuron was increased by $3 \mu \mathrm{m}$ glycine $(a)$ and reduced by $0.5 \mu \mathrm{m}$ strychnine $(b)$, and the IPSCs were eliminated by $10 \mu \mathrm{m}$ bicuculline. Time calibration in C indicates $30 \mathrm{sec}$ for $a$ and $c$ and $50 \mathrm{sec}$ for $b$. D, Time course of STR-induced depression of sIPSC frequency in C.E, For the same data, cumulative probability plots of sIPSC interevent intervals (left; K-S test, $p<0.0001$ ) and current amplitudes (right; K-S test, $p=0.95$, STR vs control). The number of events used for cumulative distributions was 240 for control and 610 for glycine during $1 \mathrm{~min}$. F, Mean percentage changes ( \pm SEM) produced by $0.5 \mu \mathrm{M}$ strychnine in four isolated neurons confirm significant reduction in IPSC frequency (left) but not amplitude (right).

slices, $3 \mu \mathrm{M}$ glycine sharply reduced the frequency of sIPSCs (Fig. 10C) but did not significantly change their amplitude. Similar results were obtained from mechanically isolated VTA cells (Fig. 10D,E): $2 \mu \mathrm{M}$ glycine reduced the sIPSC frequency by $40 \pm 6 \%(p<0.01 ; n=5)$, but their amplitude was unaltered $(13 \pm 9 \% ; p=0.07$; $n=5)$. The histograms in Figure 10 E summarize the concentration dependence of the action of glycine: 1 and $3 \mu \mathrm{m}$ glycine suppressed the sIPSC frequency by $20 \pm 7$ and $45 \pm 4 \%$ of control, respectively (in both cases, $n=4$ ), without significant change in amplitude. Such concentrations of glycine induced no or minimal postsynaptic currents (Fig. 10D). At $10 \mu \mathrm{M}$, glycine evoked a small postsynaptic current but no further decrease in sIPSC frequency (to $48 \pm 7 \%$ of control; $n=6$ ). With even higher concentrations of glycine $(30 \mu \mathrm{M}$ and above), a large postsynaptic current shunted the sIPSCs (data not shown). Bicuculline $(10 \mu \mathrm{M})$ eliminated all sIPSCs (Fig. 10C) both in the absence and presence of glycine, confirming that the observed sIPSCs were indeed GABAergic.

These data confirm the presence of GlyRs on GABAergic terminals on DA neurons of the mature VTA. In marked contrast to the situation in very young rats, in these older preparations (at 22-30 d of age), GABAergic IPSCs are depressed by glycine and enhanced by strychnine. These results suggest that glycine tends to hyperpolarize the GABAergic terminals, presumably as a result of a developmental

parable glycinergic process operates in mature animals. We therefore recorded from DA neurons of slices from 3- to 4-weekold rats, in which synaptic function is no longer immature (BenAri, 2001). In these cells, GABAergic IPSCs were also under a tonic glycinergic influence, as demonstrated by the consistent effects of strychnine, but they were in the opposite direction from those seen in neurons from immature rats: strychnine $(1 \mu \mathrm{M})$ increased eIPSCs and converted paired-pulse facilitation to depression (Fig. 9A). Overall, eIPSCs increased by $38 \pm 10 \%(n=4$; $p<0.05$ ) (Fig. $10 F$ ), and the paired-pulse ratio was reduced from $1.18 \pm 0.11$ to $0.87 \pm 0.12(p<0.05 ; n=4)$ (Fig. 9B). In mechanically isolated cells, strychnine raised sIPSC frequency (by $150 \pm 15 \%$ of control; $n=4 ; p<0.01)$ without affecting their amplitude (98 $\pm 8 \%$ of control; $p=0.9$ ) (Fig. 9C-F). The increase in mean frequency was also reflected in the cumulative frequency distributions, shifting that of sIPSC interevent intervals to the left (Fig. 9E) without affecting the distribution of sIPSC amplitudes (Fig. 9F).

The reversed effect of glycine is illustrated in Figure 10. When tested on paired IPSCs (evoked at an interval of $60 \mathrm{msec}$ ), glycine selectively inhibited the first IPSC ( eIPSC $_{1}$ ) but not the second $\left(\right.$ eIPSC $_{2}$ ), thus enhancing PPF. Overall, eIPSC ${ }_{1}$ was reduced by $39 \pm 9 \%(p<0.01 ; n=6)$ (Fig. $10 F)$ and the percentage of PPF rose from $11 \pm 1 \%$ in control tests to $82 \pm 12 \%$ in the presence of $3 \mu \mathrm{M}$ glycine $(p<0.01 ; n=6)$ (Fig. $10 B)$. This reversible change in PPF was prevented by strychnine (data not shown). Also in change in the reversal potential for the action of glycine (perhaps even more pronounced than that observed postsynaptically) (Ye, 2000). The clear effects of strychnine indicate that both in immature and mature VTA, GABAergic transmission is tonically modulated by the release of some endogenous GlyR ligand(s).

By modulating GABAergic transmission, glycine enhances the firing of DA neurons from both young and older rats

From the data presented so far, one would predict that the glycine-mediated presynaptic modulation of GABA release should have an overall excitatory effect on the DA cells. To test this hypothesis, we applied glycine $(1-100 \mu \mathrm{M})$ to spontaneously firing DA neurons in brain slices: $3 \mu \mathrm{M}$ glycine accelerated the firing of the majority ( 7 of 10) of such cells, but higher concentrations of glycine $(\geq 30 \mu \mathrm{M})$ inhibited firing, presumably because of the shunting effect of postsynaptic GlyR activation and $\mathrm{Na}^{+}$current inactivation. In Figure $11 A$, which illustrates cell firing in a slice from a very young (8-d-old) rat, one can see that the ongoing discharge, recorded in the presence of glutamate antagonists, was accelerated by glycine and depressed by BIC and STR, both of which also suppressed the effect of glycine. Similar data from six cells in slices from young rats, summarized in Figure $11 \mathrm{~B}$, confirm that the glycine-induced changes in firing were indeed mediated by conventional GlyRs on GABAergic neurons and/or terminals. The fact that bicuculline, applied alone, reduced spontaneous firing is in keeping with many previous re- 
ports that activation of $\mathrm{GABA}_{\mathrm{A}}$ receptors $\left(\mathrm{GABA}_{\mathrm{A}} \mathrm{Rs}\right)$ excites immature neurons. By facilitating GABAergic excitation, ongoing release of glycine and/or taurine plays a substantial role in the mechanism of the spontaneous discharge of DA neurons.

Similar tests on slices from older rats (22-30 d of age) are illustrated in Figure $11, C$ and $D$. As expected, in these slices, the action of bicuculline was reversed, being excitatory (disinhibitory), as is normally the case in mature preparations. In contrast, $3 \mu \mathrm{M}$ glycine was excitatory, as in the slices from young rats, and this effect was much masked when glycine was applied in the presence of bicuculline. Only at a much higher concentration $(20 \mu \mathrm{M})$ did glycine cause inhibition, presumably via the postsynaptic GlyRs. The results of such tests on four neurons in adult slices are summarized in Figure $11 D$. In keeping with our findings on IPSCs, these data confirm that strychnine-sensitive presynaptic GlyRs also modulate GABAergic transmission in mature slices. However, because the actions of both glycine and GABA are reversed, and now glycine reduces inhibition of the DA cells, the net result is facilitation of firing, as in the young preparations. The major occlusion of the effect of glycine by bicuculline indicates that this facilitation operates mainly via changes in GABAergic activity.

\section{Discussion}

In DA neurons of VTA from very young rats, bicuculline-sensitive IPSCs are facilitated by glycine and taurine at concentrations that have virtually no postsynaptic action. This strychnine-sensitive facilitation (seen both in midbrain slices and in mechanically isolated cells) is manifested by larger electrically evoked IPSCs and more frequent spontaneous IPSCs. In keeping with a presynaptic site of glycinergic action, paired-pulse facilitation of IPSCs is reduced, and $\mathrm{Ca}^{2+}$ imaging shows that glycine enhances $\left[\mathrm{Ca}^{2+}\right]$ in synaptic boutons on DA neurons. These effects of glycine are much reduced by tetrodotoxin, $\mathrm{Cd}^{2+}$, or lack of $\mathrm{Ca}^{2+}$, indicating a major role of voltage-dependent $\mathrm{Na}^{+}$and $\mathrm{Ca}^{2+}$ channels. As strychnine depresses both spontaneous and evoked IPSCs, GABAergic transmission is tonically facilitated by ongoing release of an endogenous glycine agonist. In contrast, in VTA from older rats (22-30 d of age), the tonic presynaptic glycinergic action depresses GABAergic inhibition. Hence, the overall effect of the presynaptic action of glycine is to promote firing of most DA cells both in very young and in more mature rats.

\section{Functional presynaptic GlyRs}

In the mature VTA, intrinsic GABAergic neurons inhibit DA neurons via $\mathrm{GABA}_{\mathrm{A}}$ receptors (Johnson and North, 1992; Xi and Stein, 1998) and also project to various brain regions involved in behavioral reward (Semba and Fibiger, 1992; Van Bockstaele and Pickel, 1995). In agreement with previous electrophysiological data (Bonci and Williams, 1997), we observed numerous bicuculline-sensitive IPSCs in DA neurons from both very young and older rats.

Functional GlyRs are known to be present on most VTA neurons (Ye et al., 1998). The current results show that there are also presynaptic GlyRs, which modulate GABAergic activity. A high density of presynaptic GlyRs may account for the fact that low concentrations ( $\leq 3 \mu \mathrm{M}$ ) of glycine alter sIPSC frequency without eliciting significant postsynaptic responses. An alternative explanation may be their greater sensitivity to glycine, probably because of a different subtype composition. According to expression studies, $\alpha$-homomeric GlyRs may be more sensitive than $\alpha \beta$-heteromeric GlyRs (Bormann et al., 1993; Handford et al., 1996). Differential presynaptic and postsynaptic actions of picrotoxin indicate different properties of presynaptic and postsynaptic GlyRs in the spinal cord (Jeong et al., 2003).

A great variety of agents can modulate transmitter release through different cellular mechanisms (MacDermott et al., 1999). A given transmitter, acting on the same receptors, can have opposite actions at different sites. For example, in the spinal cord, $\mathrm{GABA}_{\mathrm{A}}$ Rs mediate the well known presynaptic inhibition at the primary sensory relay (Eccles et al., 1963), but they facilitate transmission at some glycinergic synapses (Jang et al., 2002), al- 


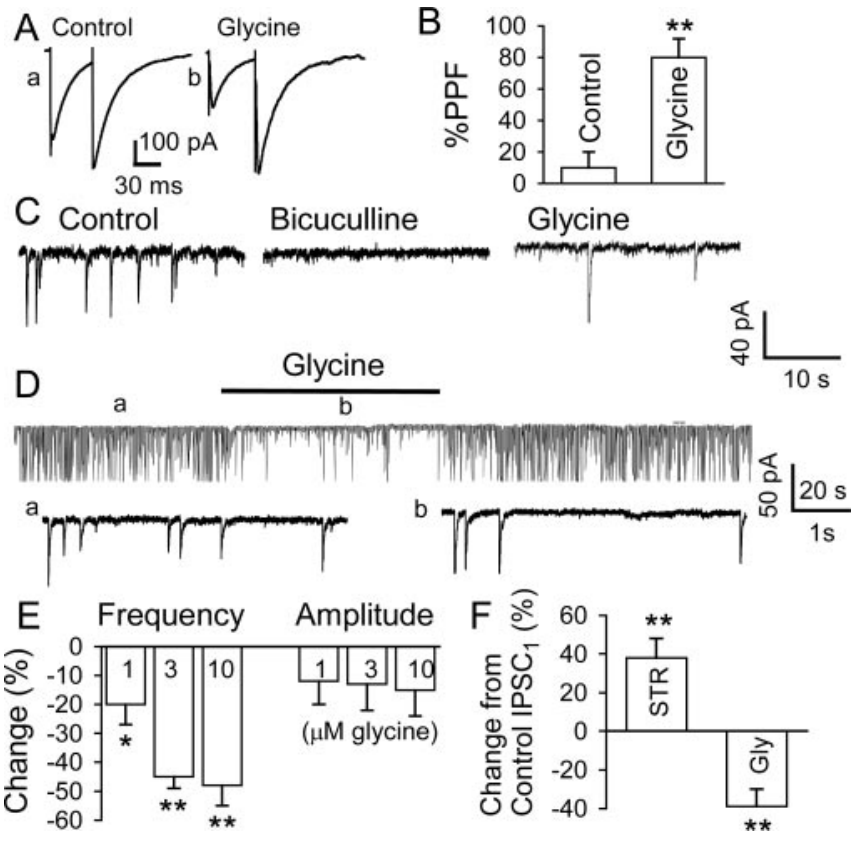

Figure 10. Glycine depresses spontaneous and evoked IPSCs in VTA DA neurons from 22- to 30-d-old rats: data are from slices $(A-C)$ and isolated nerve-bouton preparations $(D, E) . A$, GABAergic elPSCs obtained in response to paired-pulse stimulation (at $60 \mathrm{msec}$ interval) in control conditions $(A a)$ and in the presence of $10 \mu \mathrm{m}$ glycine $(A b)$. Glycine diminished the first IPSC and increased paired-pulse facilitation. Traces are averages of 10; all were recorded from the same DA neuron at a $V_{\mathrm{h}}$ of $-70 \mathrm{mV}$. B, Summary of data from six neurons treated as in $A$ $\left({ }^{* *} p<0.01\right)$. C, sIPSC recorded in a slice before and during the application of $10 \mu \mathrm{m}$ bicuculline or $2 \mu \mathrm{m}$ glycine. D, sIPSCS recorded from a nerve-bouton preparation before, during, and after the application of $2 \mu \mathrm{m}$ glycine. For clarity, the sIPSCS were truncated; traces below $(a, b)$ are parts of trace in $D$ (as indicated) on an expanded time scale. $E$, Percentage change in mean frequency and amplitude of sIPSCs induced by 1,3 , and $10 \mu \mathrm{m}$ glycine $(n=5)$. Percentage change was calculated as $100 \times\left[\left(\operatorname{IPSC}_{\text {glycine }} / I P S C_{\text {control }}\right)-1\right]$, where IPSC $C_{\text {glycine }}$ and IPSC are the frequency or amplitude of the spontaneous IPSCs recorded in the presence and absence of glycine. Throughout, the ACSF contained DNQX $(20 \mu \mathrm{M})$ and APV $(100 \mu \mathrm{M})$ to minimize indirect effects mediated by glutamatergic synapses. $F$, Summary of effects of strychnine and glycine on IPSCS recorded in older neurons ( $n=4$ and 6 ; ${ }^{* *} p<0.01$ ).

though at both sites, GABA causes depolarization. The overall effect presumably depends on the balance between synaptic facilitation by the rise in intra-axonal $\left[\mathrm{Na}^{+}\right]$and $\left[\mathrm{Ca}^{2+}\right]$ and depression of $\mathrm{Ca}^{2+}$ influx by excessive depolarization and inward current inactivation (Thompson et al., 1993; Wu and Saggau, 1997; Zucker and Regehr, 2002).

The presynaptic actions of glycine are equally unpredictable. Although strychnine-sensitive GlyRs inhibit vasopressin release from supraoptic terminals (Hussy et al., 2001), they facilitate synaptic transmission in the pons and the cerebellar cortex (Turecek and Trussell, 2001; Kawa, 2003). Even in the VTA, in preparations from older rats (at 22-30 d of age), endogenous glycine (and/or taurine) inhibits GABAergic transmission. Clearly, one cannot predict on the basis of simple analogy how presynaptic modulation operates at different synapses or at different stages of development.

\section{Mechanism and site of presynaptic action of glycine}

Because of an outward $\mathrm{Cl}^{-}$gradient, glycine, like GABA (Mueller et al., 1984; Cherubini et al., 1991), has a depolarizing and excitatory postsynaptic action in newborn rats, notably in the VTA (Ye, 2000). A similar outward $\mathrm{Cl}^{-}$gradient mediates the GlyR-dependent terminal depolarization observed in a pontine nucleus (Turecek and Trussell, 2001). We presume that the pre-
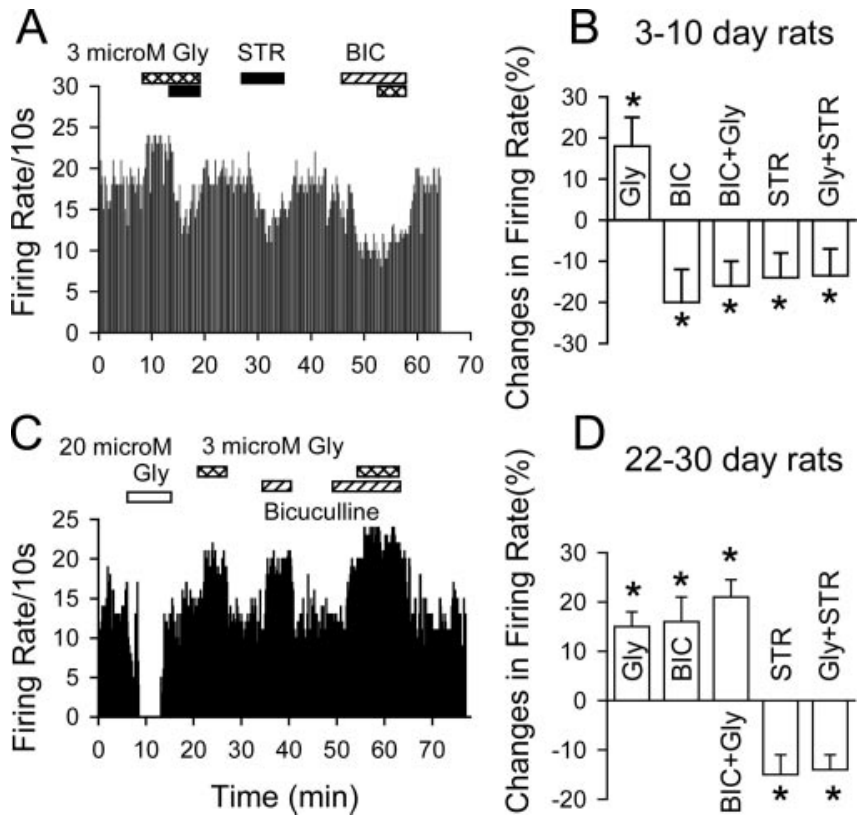

Figure 11. Glycine enhances rate of firing of VTA DA neurons in slices from both young and older rats. Recordings were throughout in the presence of APV $(100 \mu \mathrm{M})$ and DNQX $(20 \mu \mathrm{M})$ to minimize indirect effects mediated by glutamatergic synapses. $A$, Ongoing discharge of VTA DA neuron in midbrain slice from an 8-d-old rat recorded in the loose-patch cell-attached configuration at $33^{\circ} \mathrm{C}$. DA neurons were identified by their inhibitory response to the application of dopamine (data not shown). Increased firing elicited by low concentration of glycine $(3 \mu \mathrm{M})$ was suppressed by BIC $(10 \mu \mathrm{M})$. Both STR $(1 \mu \mathrm{M})$ and bicuculline attenuated the ongoing discharge. $B$, Mean changes ( \pm SEM) in firing rate observed in six neurons. For this and for $D$, data were collected for 60 sec; in paired $t$ tests, each neuron served as its own control. C, Ongoing discharge of a VTA DA neuron in midbrain slice from a 30-d-old rat was suppressed by high concentration of glycine $(20 \mu \mathrm{M})$ and clearly enhanced by low concentration of glycine $(3 \mu \mathrm{M})$. Bicuculline $(10 \mu \mathrm{M})$ causes similar excitation, which masks the effect of glycine. D, Summary of the effects of $3 \mu \mathrm{m}$ glycine and other agents observed in four neurons from older rats. Note that although bicuculline effects are reversed in older rats, glycine causes a similar facilitation of firing in slices from very young and more mature rats. For the paired $t$ tests, each neuron served as its own control $\left({ }^{*} p<0.05\right)$. In each test, data were collected for $60 \mathrm{sec}$.

synaptic facilitation of IPSCs observed in preparations from young rats is also initiated by $\mathrm{Cl}^{-}$efflux from GABAergic axons, and that a maturational reversal of the $\mathrm{Cl}^{-}$gradient accounts for the reversed glycinergic effect seen in adult preparations. In contrast to primary sensory axons in the mature spinal cord, where $\mathrm{Cl}^{-}$transport maintains the outward $\mathrm{Cl}^{-}$gradient that generates depolarizing dorsal root potentials, in these GABAergic axons, $\mathrm{Cl}^{-}$transport maintains an inward $\mathrm{Cl}^{-}$gradient.

Judging by the inconstant effects of TTX, the precise location of presynaptic GlyRs may vary between different sites. Thus, TTX abolished the comparable facilitation of glycinergic IPSCs in spinal nerve-bouton preparations (Jeong et al., 2003) and EPSCs in cerebellar slices (Kawa, 2003) but only half-suppressed the facilitation of glycinergic IPSCs recorded in the same cells. As proposed by Kawa (2003), different distributions of GlyRs between terminal and preterminal sites probably account for this variability. In the immature VTA, glycine appears to act at a preterminal site of many axons, and TTX-sensitive $\mathrm{Na}^{+}$currents are needed to conduct the initial signal to the terminal where it activates the voltage-dependent $\mathrm{Ca}^{2+}$ influx that triggers GABA release, in keeping with the observed suppression of sIPSPs by $\mathrm{Cd}^{2+}$.

In general agreement with the electrophysiological findings, $\mathrm{Ca}^{2+}$-imaging experiments provided more direct evidence that glycine can generate $\left[\mathrm{Ca}^{2+}\right]$ influx. After differential loading with fura-2, clear spots can be seen on the edge or surface of DA 
neurons corresponding to presynaptic terminals, as confirmed by overlapping staining with the presynaptic marker FM1-43 (Cochilla et al., 1999; Akaike and Moorhouse, 2003). The fura-2 signals of such spots were enhanced by glycine. The selective suppression of this effect by $\omega$-conotoxin MVIIA, but not nimodipine, indicated the predominant involvement of $\mathrm{N}$ - and $\mathrm{P} / \mathrm{Q}$-type $\mathrm{Ca}^{2+}$ channels, in general agreement with the findings of Rhee et al. (1999) on IPSCs in nerve-bouton preparations from Meynert neurons. In the medial nucleus of the trapezoid body, Turecek and Trussell (2001) found that depolarization raised intraterminal $\left[\mathrm{Ca}^{2+}\right]$, but a glycine-induced increase of intraterminal $\left[\mathrm{Ca}^{2+}\right]$ has not been demonstrated.

\section{Tonic glycine or taurine release influences GABAergic synapses}

A tonic release of some endogenous $\mathrm{GABA}_{\mathrm{A}} \mathrm{R}$ agonist regulates the excitability of hippocampal neurons (Yeung et al., 2003). At pontine calyx synapses, glycine spills over to adjacent synapses and facilitates glutamate release (Turecek and Trussell, 2001). During repetitive stimulation of spinal glycinergic synapses, glycine spillover facilitates glycine release via autoreceptors (Jeong et al., 2003). In our experiments on VTA, strychnine revealed an ongoing glycinergic modulation of GABAergic IPSCs. Note that the tonic glycinergic tone was also observed in slices kept at $33^{\circ} \mathrm{C}$, where glycine uptake mechanisms are expected to be more active, making it more likely to be relevant for the VTA in vivo.

Because the VTA contains relatively few glycine-immunoreactive elements (Rampon et al., 1996), some other glycine agonist(s) may account for much of the observed glycinergic tone. Taurine is known to be a glycine agonist in the VTA (Wang and Ye, 2003). It is abundant throughout the brain (Jacobsen and Smith, 1968; Madsen et al., 1987; Huxtable, 1992; Dahchour et al., 1996), especially in newborn animals (Sturman, 1993). Whether released from adjacent neurons, fibers, or glia, as in the neurohypophysis where taurine release from glia mediates osmoregulation via vasopressin release (Hussy et al., 2001), taurine could be an important endogenous ligand for the presynaptic GlyRs in VTA.

The glycinergic tone differs remarkably between DA neurons from very young (3-10 d of age) and older (22-30 d of age) rats; in the former, GABAergic IPSCs are facilitated and in the latter, they are inhibited. Although the glycinergic presynaptic action is reversed with maturation, the overall consequence for DA neuronal activity does not change. In the early postnatal period, the glycinergic tone reinforces GABAergic excitation; after maturation, which is accompanied by a reversal of action of GABA from excitation to inhibition, the glycinergic tone is disinhibitory. In both cases, the excitability of DA neurons is enhanced.

\section{Significance of glycinergic facilitation in the newborn}

In the early postnatal period when other transmitters are not yet operative (Gaiarsa et al., 2002) and neuronal and synaptic growth and maturation are driven mainly by GABA-induced $\mathrm{Ca}^{2+}$ influx (Reichling et al., 1994; Ben-Ari, 2001), the ongoing facilitation of GABA release could have a significant impact on orderly development. The consequences are likely to be serious if the glycinergic action is potentiated by ethanol (Aguayo and Pancetti, 1994; Eggers et al., 2000; Ye et al., 2001), especially during the perinatal period (Sturman, 1993) when taurine release is exceptionally high and, moreover, is increased by ethanol (Dahchour et al., 1996; Olive, 2002). A well known result of maternal ethanol addiction is the "fetal alcohol syndrome," associated with brain malformation and mental retardation (Clarren and Smith, 1978; Mattson et al., 2001). Blockage of $\mathrm{GABA}_{\mathrm{A}}$ receptors in the VTA reduces ethanol consumption (Nowak et al., 1998). Hence, in the adult, glycinergic inhibition of GABA release may act as a brake on addictive behavior.

\section{References}

Aguayo LG, Pancetti FC (1994) Ethanol modulation of the gammaaminobutyric acidA- and glycine-activated Cl-current in cultured mouse neurons. J Pharmacol Exp Ther 270:61-69.

Akaike N, Moorhouse AJ (2003) (2003) Techniques: applications of the nerve-bouton preparation in neuropharmacology. Trends Pharmacol Sci 24:44-47.

Barry P (1996) Axoscope junction potential calculator. Axobits 18:3-4.

Ben-Ari Y (2001) Developing networks play a similar melody. Trends Neurosci 24:353-360.

Ben-Ari Y, Khazipov R, Leinekugel X, Caillard O, Gaiarsa JL (1997) GABAA, NMDA and AMPA receptors: a developmentally regulated "ménage à trois." Trends Neurosci 20:523-529.

Betz H (1991) Glycine receptors: heterogeneous and widespread in the mammalian brain. Trends Neurosci 14:458-461.

Bonci A, Malenka RC (1999) Properties and plasticity of excitatory synapses on dopaminergic and GABAergic cells in the ventral tegmental area. J Neurosci 19:3723-3730.

Bonci A, Williams JT (1997) Increased probability of GABA release during withdrawal from morphine. J Neurosci 17:796-803.

Bormann J, Rundstrom N, Betz H, Langosch D (1993) Residues within transmembrane segment M2 determine chloride conductance of glycine receptor homo- and hetero-oligomers. EMBO J 12:3729-3737.

Brickley SG, Cull-Candy SG, Farrant M (1996) Development of a tonic form of synaptic inhibition in rat cerebellar granule cells resulting from persistent activation of GABAA receptors. J Physiol (Lond) 497:753-759.

Brodie MS, Pesold C, Appel SB (1999) Ethanol directly excites dopaminergic ventral tegmental area reward neurons. Alcohol Clin Exp Res 23:1848-1852.

Carta M, Mameli M, Valenzuela CF (2004) Alcohol enhances GABAergic transmission to cerebellar granule cells via an increase in Golgi cell excitability. J Neurosci 24:3746-3751.

Casado M, Dieudonne S, Ascher P (2000) Presynaptic N-methyl-Daspartate receptors at the parallel fiber-Purkinje cell synapse. Proc Natl Acad Sci USA 97:11593-11597.

Cherubini E, Gaiarsa JL, Ben-Ari Y (1991) GABA: an excitatory transmitter in early postnatal life. Trends Neurosci 14:515-519.

Clarren SK, Smith DW (1978) The fetal alcohol syndrome. N Engl J Med 298:1063-1067.

Cochilla AJ, Angleson JK, Betz WJ (1999) Monitoring secretory membrane with FM1-43 fluorescence. Annu Rev Neurosci 22:1-10.

Dahchour A, Quertemont E, De Witte P (1996) Taurine increases in the nucleus accumbens microdialysate after acute ethanol administration to naive and chronically alcoholised rats. Brain Res 735:9-19.

Druzin M, Haage D, Malinina E, Johansson S (2002) Dual and opposing roles of presynaptic $\mathrm{Ca}^{2+}$ influx for spontaneous GABA release from rat medial preoptic nerve terminals. J Physiol (Lond) 542:131-146.

Eccles JC, Schmidt R, Willis WD (1963) Pharmacological studies on presynaptic inhibition. J Physiol (Lond) 168:500-530.

Eggers ED, O’Brien JA, Berger AJ (2000) Developmental changes in the modulation of synaptic glycine receptors by ethanol. J Neurophysiol 84:2409-2416.

Ehrlich I, Lohrke S, Friauf E (1999) Shift from depolarizing to hyperpolarizing glycine action in rat auditory neurones is due to age-dependent Cl-regulation. J Physiol (Lond) 520:121-137.

Feng ZP, Doering CJ, Winkfein RJ, Beedle AM, Spafford JD, Zamponi GW (2003) Determinants of inhibition of transiently expressed voltage-gated calcium channels by omega-conotoxins GVIA and MVIIA. J Biol Chem 278:20171-20178.

Flint AC, Liu X, Kriegstein AR (1998) Nonsynaptic glycine receptor activation during early neocortical development. Neuron 20:43-53.

Frerking M, Nicoll RA (2000) Synaptic kainate receptors. Curr Opin Neurobiol 10:342-351.

Gaiarsa JL, Caillard O, Ben-Ari Y (2002) Long-term plasticity at GABAergic and glycinergic synapses: mechanisms and functional significance. Trends Neurosci 25:564-570.

Gatto GJ, McBride WJ, Murphy JM, Lumeng L, Li TK (1994) Ethanol self- 
infusion into the ventral tegmental area by alcohol-preferring rats. Alcohol 11:557-564.

Grace AA (1988) In vivo and in vitro intracellular recordings from rat midbrain dopamine neurons. Ann NY Acad Sci 537:51-76.

Grace AA, Onn SP (1989) Morphology and electrophysiological properties of immunocytochemically identified rat dopamine neurons recorded in vitro. J Neurosci 9:3463-3481.

Handford CA, Lynch JW, Baker E, Webb GC, Ford JH, Sutherland GR, Schofield PR (1996) The human glycine receptor beta subunit: primary structure, functional characterisation and chromosomal localisation of the human and murine genes. Brain Res Mol Brain Res 35:211-219.

Hussy N, Bres V, Rochette M, Duvoid A, Alonso G, Dayanithi G, Moos FC (2001) Osmoregulation of vasopressin secretion via activation of neurohypophysial nerve terminals glycine receptors by glial taurine. J Neurosci 21:7110-7116.

Huxtable RJ (1992) Physiological actions of taurine. Physiol Rev 72:101-163.

Jacobsen JG, Smith LH (1968) Biochemistry and physiology of taurine and taurine derivatives. Physiol Rev 48:424-511.

Jang IS, Jeong HJ, Katsurabayashi S, Akaike N (2002) Functional roles of presynaptic $\mathrm{GABA}(\mathrm{A})$ receptors on glycinergic nerve terminals in the rat spinal cord. J Physiol (Lond) 541:423-434.

Jeong HJ, Jang IS, Moorhouse AJ, Akaike N (2003) Activation of presynaptic glycine receptors facilitates glycine release from presynaptic terminals synapsing onto rat spinal sacral dorsal commissural nucleus neurons. J Physiol (Lond) 550:373-383.

Jiang Z, Krnjević K, Wang F, Ye JH (2004) Taurine activates strychninesensitive glycine receptors in neurons freshly isolated from nucleus Accumbens of young rats. J Neurophysiol 91:247-258.

Johnson SW, North RA (1992) Two types of neurone in the rat ventral tegmental area and their synaptic inputs. J Physiol (Lond) 450:455-468.

Kawa K (2003) Glycine facilitates transmitter release at developing synapses: a patch clamp study from Purkinje neurons of the newborn rat. Dev Brain Res 144:57-71.

Kilb W, Ikeda M, Uchida K, Okabe A, Fukuda A, Luhmann HJ (2002) Depolarizing glycine responses in Cajal-Retzius cells of neonatal rat cerebral cortex. Neuroscience 112:299-307.

Kondo S, Marty A (1998) Differential effects of noradrenaline on evoked, spontaneous and miniature IPSCs in rat cerebellar stellate cells. J Physiol (Lond) 509:233-243.

Krnjević K (1974) Chemical nature of synaptic transmission in vertebrates. Physiol Rev 54:418-540.

Kuhse J, Betz H, Kirsch J (1995) The inhibitory glycine receptor: architecture, synaptic localization and molecular pathology of a postsynaptic ionchannel complex. Curr Opin Neurobiol 5:318-323.

Laube B, Maksay G, Schemm R, Betz H (2002) Modulation of glycine receptor function: a novel approach for therapeutic intervention at inhibitory synapses? Trends Pharmacol Sci 23:519-527.

Lerma J (1997) Kainate reveals its targets. Neuron 19:1155-1158.

Liley AW (1956) The effects of presynaptic polarization on the spontaneous activity at the mammalian neuromuscular junction. J Physiol (Lond) 134:427-443.

LoTurco JJ, Owens DF, Heath MJ, Davis MB, Kriegstein AR (1995) GABA and glutamate depolarize cortical progenitor cells and inhibit DNA synthesis. Neuron 15:1287-1298.

MacDermott AB, Role LW, Siegelbaum SA (1999) Presynaptic ionotropic receptors and the control of transmitter release. Annu Rev Neurosci 22:443-485.

Madsen S, Ottersen OP, Storm-Mathisen J (1987) Immunocytochemical demonstration of taurine. Adv Exp Med Biol 217:275-284.

Mansvelder HD, Keath JR, McGehee DS (2002) Synaptic mechanisms underlie nicotine-induced excitability of brain reward areas. Neuron 33:905-919.

Mattson SN, Schoenfeld AM, Riley EP (2001) Teratogenic effects of alcohol on brain and behavior. Alcohol Res Health 25:185-191.

McGehee DS, Role LW (1996) Presynaptic ionotropic receptors. Curr Opin Neurobiol 6:342-349.

Melis M, Camarini R, Ungless MA, Bonci A (2002) Long-lasting potentiation of GABAergic synapses in dopamine neurons after a single in vivo ethanol exposure. J Neurosci 22:2074-2082.

Mennerick S, Zorumski CF (1995) Paired-pulse modulation of fast excita- tory synaptic currents in microcultures of rat hippocampal neurons. J Physiol (Lond) 488:85-101.

Mercuri NB, Calabresi P, Bernardi G (1990) Responses of rat substantia nigra compacta neurones to L-DOPA. Br J Pharmacol 100:257-260.

Mueller AL, Taube JS, Schwartzkroin PA (1984) Development of hyperpolarizing inhibitory postsynaptic potentials and hyperpolarizing response to gamma-aminobutyric acid in rabbit hippocampus studied in vitro. J Neurosci 4:860-867.

Nicoll RA, Malenka RC, Kauer JA (1990) Functional comparison of neurotransmitter receptor subtypes in mammalian central nervous system. Physiol Rev 70:513-565.

Nowak KL, McBride WJ, Lumeng L, Li TK, Murphy JM (1998) Blocking $\mathrm{GABA}(\mathrm{A})$ receptors in the anterior ventral tegmental area attenuates ethanol intake of the alcohol-preferring P rat. Psychopharmacology (Berl) 139:108-116.

Olive MF (2002) Interactions between taurine and ethanol in the central nervous system. Amino Acids 23:345-357.

Rampon C, Luppi PH, Fort P, Peyron C, Jouvet M (1996) Distribution of glycine-immunoreactive cell bodies and fibers in the rat brain. Neuroscience 75:737-755.

Reichling DB, Kyrozis A, Wang J, MacDermott AB (1994) Mechanisms of GABA and glycine depolarization-induced calcium transients in rat dorsal horn neurons. J Physiol Lond 476:411-421.

Reid CA, Bekkers JM, Clements JD (2003) Presynaptic $\mathrm{Ca}^{2+}$ channels: a functional patchwork. Trends Neurosci 26:683-687.

Rhee JS, Ishibashi H, Akaike N (1999) Calcium channels in the GABAergic presynaptic nerve terminals projecting to Meynert neurons of the rat. J Neurochem 72:800-807.

Rivera C, Voipio J, Payne JA, Ruusuvuori E, Lahtinen H, Lamsa K, Pirvola U, Saarma M, Kaila K (1999) The $\mathrm{K}^{+} / \mathrm{Cl}^{-}$co-transporter KCC2 renders GABA hyperpolarizing during neuronal maturation. Nature 397:251-255.

Rodd ZA, Melendez RI, Bell RL, Kuc KA, Zhang Y, Murphy JM, McBride WJ (2004) Intracranial self-administration of ethanol within the ventral tegmental area of male Wistar rats: evidence for involvement of dopamine neurons. J Neurosci 24:1050-1057.

Salin PA, Malenka RC, Nicoll RA (1996) Cyclic AMP mediates a presynaptic form of LTP at cerebellar parallel fiber synapses. Neuron 16:797-803.

Satake S, Saitow F, Yamada J, Konishi S (2000) Synaptic activation of AMPA receptors inhibits GABA release from cerebellar interneurons. Nat Neurosci 3:551-558.

Semba K, Fibiger HC (1992) Afferent connections of the laterodorsal and the pedunculopontine tegmental nuclei in the rat: a retro- and anterograde transport and immunohistochemical study. J Comp Neurol 323:387-410.

Semyanov A, Walker MC, Kullmann DM, Silver RA (2004) Tonically active GABA(A) receptors: modulating gain and maintaining the tone. Trends Neurosci 27:262-269.

Steffensen SC, Svingos AL, Pickel VM, Henriksen SJ (1998) Electrophysiological characterization of GABAergic neurons in the ventral tegmental area. J Neurosci 18:8003-8015.

Sturman JA (1993) Taurine in development. Physiol Rev 73:119-147.

Tepper JM, Paladini CA, Celada P (1998) GABAergic control of the firing pattern of substantia nigra dopaminergic neurons. Adv Pharmacol 42:694-699.

Thompson SM, Capogna M, Scanziani M (1993) Presynaptic inhibition in the hippocampus. Trends Neurosci 16:222-227.

Turecek R, Trussell LO (2001) Presynaptic glycine receptors enhance transmitter release at a mammalian central synapse. Nature 411:587-590.

Van Bockstaele EJ, Pickel VM (1995) GABA-containing neurons in the ventral tegmental area project to the nucleus accumbens in rat brain. Brain Res 682:215-221.

Wang F, Ye JH (2003) Taurine activates nonsynaptic glycine receptors of dopaminergic neurons of ventral tegmental area of young rats. Soc Neurosci Abstr 29:572.2.

Werman R, Davidoff RA, Aprison MH (1968) Inhibitory action of glycine on spinal neurons in the cat. J Neurophysiol 31:81-95.

Wise RA (1996) Addictive drugs and brain stimulation reward. Annu Rev Neurosci 19:319-340.

Wu LG, Saggau P (1997) Presynaptic inhibition of elicited neurotransmitter release. Trends Neurosci 20:204-212.

Xi ZX, Stein EA (1998) Nucleus accumbens dopamine release modulation 
by mesolimbic $\mathrm{GABA}_{\mathrm{A}}$ receptors-an in vivo electrochemical study. Brain Res 798:156-165.

Xiong Z, O'Hanlon D, Becker LE, Roder J, MacDonald JF, Marks A (2000) Enhanced calcium transients in glial cells in neonatal cerebellar cultures derived from S100B null mice. Exp Cell Res 257:281-289.

Ye J (2000) Physiology and pharmacology of native glycine receptors in developing rat ventral tegmental area neurons. Brain Res 862:74-82.

Ye JH, Ren J, Liu PL, McArdle JJ (1998) Glycine-activated chloride currents of neurons freshly isolated from the ventral tegmental area of rats. Brain Res 796:53-62.

Ye JH, Tao L, Ren J, Schaefer R, Krnjević K, Liu PL, Schiller DA, McArdle JJ (2001) Ethanol potentiation of glycine-induced responses in dissociated neurons of rat ventral tegmental area. J Pharmacol Exp Ther 296:77-83.

Ye JH, Wang F, Krnjević K, Wang W, Xiong Z (2004) Presynaptic glycine receptors on GABAergic terminals facilitate discharge of VTA dopaminergic neurons. Soc Neurosci Abstr 30:735.19.

Yeung JY, Canning KJ, Zhu G, Pennefather P, MacDonald JF, Orser BA (2003) Tonically activated $\mathrm{GABA}_{\mathrm{A}}$ receptors in hippocampal neurons are high-affinity, low-conductance sensors for extracellular GABA. Mol Pharmacol 63:2-8.

Zheng F, Johnson SW (2001) Glycine receptor-mediated inhibition of dopamine and non-dopamine neurons of the rat ventral tegmental area in vitro. Brain Res 919:313-317.

Zhou ZJ (2001) A critical role of the strychnine-sensitive glycinergic system in spontaneous retinal waves of the developing rabbit. J Neurosci 21:5158-5168.

Zucker RS, Regehr WG (2002) Short-term synaptic plasticity. Annu Rev Physiol 64:355-405. 